\title{
Blindsight is qualitatively degraded conscious vision
}

\author{
Ian Phillips ${ }^{1}$ \\ ${ }^{1}$ Departments of Philosophy and Psychological and Brain Sciences, Johns Hopkins University
}

Copyright (C) 2020, American Psychological Association. This paper is not the copy of record and may not exactly replicate the final, authoritative version of the article. Please do not copy or cite without permission. The final article will be available, upon publication, via its DOI: $10.1037 /$ rev0000254

\begin{abstract}
Author Note
Portions of this material have been presented at Princeton, Brown, University of Alabama, Johns Hopkins, University of Tokyo, and Osaka City University. I am most grateful to audiences on all those occasions. Special thanks to Will Davies, Chaz Firestone, Steven Gross, and Hanna Pickard for very helpful comments on an earlier draft. Thanks also to the Editor and to three reviewers for this journal, amongst them Michael Snodgrass and Hakwan Lau, for their extremely constructive reports which led to substantial improvements to the paper. I owe a continuing debt of gratitude to Paul Azzopardi for first stimulating my thinking on these issues.
\end{abstract}

Correspondence concerning this article should be addressed to Ian Phillips, Department of Philosophy, Johns Hopkins University, Baltimore, Maryland 21218, United States. 


\begin{abstract}
Blindsight is a neuropsychological condition defined by residual visual function following destruction of primary visual cortex. This residual visual function is almost universally held to include capacities for voluntary discrimination in the total absence of awareness. So conceived, blindsight has had an enormous impact on the scientific study of consciousness. It is held to reveal a dramatic disconnect between performance and awareness and used to motivate diverse claims concerning the neural and cognitive basis of consciousness. Here I argue that this orthodox understanding of blindsight is fundamentally mistaken. Drawing on models from signal detection theory in conjunction with a wide range of behavioral and first-person evidence, I contend that blindsight is severely and qualitatively degraded but nonetheless conscious vision, unacknowledged due to conservative response biases. Psychophysical and functional arguments to the contrary are answered. A powerful positive case for the qualitatively degraded conscious vision hypothesis is then presented, detailing a set of distinctive predictions borne out by the data. Such data are further used to address the question of what it is like to have blindsight, as well as to explain the conservative and selectively unstable response criteria exhibited by blindsight subjects. On the view defended, blindsight does not reveal any dissociation between performance and awareness, nor does it speak to the neural or cognitive requirements for consciousness. A foundation stone of consciousness science requires radical reconsideration.
\end{abstract}

Keywords: blindsight, awareness, degraded conscious vision, signal detection theory, response criteria 


\section{Blindsight is qualitatively degraded conscious vision}

Blindsight is a neuropsychological condition defined by residual visual function following partial or complete destruction of primary visual cortex (Pöppel et al, 1973; Weiskrantz et al., 1974). Most theorists consider this residual visual function to include capacities for voluntary discrimination in the total absence of awareness. So conceived, blindsight has had a remarkable impact on the scientific and philosophical study of consciousness. Blindsight has overthrown the traditional view that intentional discrimination requires awareness of the discriminandum, and is widely relied on to support diverse claims about the cognitive and neural basis of consciousness. After half a century, it remains 'the clinical condition ... most often discussed in the context of the contemporary science of consciousness' (LeDoux et al., 2020: 6981) and 'central to current debates about the nature of consciousness in humans' (ibid., 6979).

Against this tide, a handful of critics have long suggested that the dominant understanding of blindsight may be mistaken. According to these critics, blindsight may instead be severely and qualitatively degraded but nonetheless conscious vision, unacknowledged due to conservative response biases. Call this the qualitatively degraded conscious vision hypothesis (henceforth: QDC). If correct, blindsight would not be revolutionary at all. It would not reveal any dissociation between intentional discrimination and awareness, nor would it speak to the neurological or cognitive requirements for consciousness. A foundation stone of contemporary consciousness studies would require radical reconsideration.

QDC is widely regarded as ill-motivated and empirically inadequate. Here I offer a systematic and sustained defense. I explain why familiar empirical arguments against QDC are ineffectual. I then mount a powerful, positive case for the hypothesis, detailing a set of 
distinctive predictions borne out by the available behavioral and first-personal data. This evidence not only strongly supports QDC but helps us appreciate what it may be like to have blindsight (Nagel, 1974).

Throughout I focus exclusively on cases of blindsight involving intentional discrimination. It is these cases-as opposed, e.g., to intact ocular reflexes (Weiskrantz et al., 1999) or indirect effects on action due to bilateral summation (de Gelder et al., 2001)—which generate the primary interest in blindsight from the perspective of the scientific and philosophical study of consciousness. ${ }^{1}$ I also focus on blindsight in humans.

Discussion is structured as follows. Section one offers a brief review and introduces two opposing interpretations of blindsight. First, a canonical, inflationary interpretation on which blindsight involves preserved capacities for voluntary visual discrimination operating outside awareness. Second, a heterodox, deflationary interpretation on which blindsight involves only qualitatively degraded conscious vision unreported due to conservative response biases (QDC). (Those familiar with blindsight and the present controversy may wish to skim this section.) Section two answers five leading criticisms of QDC which have convinced many theorists that the hypothesis is untenable. Though unsuccessful, these criticisms highlight two features which

\footnotetext{
${ }^{1}$ Danckert and Rossetti (2005) distinguish three types of blindsight: action-blindsight, attention-blindsight and agnosopsia (see also Zeki \& ffytche, 1998: 41) based on various neural and behavioural criteria. The residual ability to intentionally discriminate stimuli crosscuts this taxonomy. It includes motion discrimination which Danckert and Rossetti class as attention-blindsight but excludes mere priming effects which they consider evidence of agnosopsia. The ability to intentionally discriminate also excludes action-blindsight to the extent that this comprises online motor-control subserved by 'a parietal automatic pilot' (Pisella et al., 2000; though see Footnote 38) as opposed to intentional discrimination proper.
} 
any account of blindsight must explain. First, the fact that blindsight subjects adopt abnormally conservative criteria in their blindfields. Second, the fact that these criteria are unstable in specific relation to static stimuli. Section three then makes the positive case for QDC, showing that its distinctive predictions are borne out by the available evidence, and addressing the question: what is it like to have blindsight? It is further explained how QDC can account for blindsighters' characteristically conservative and unstable criteria. The paper closes by highlighting the implications for the scientific study of consciousness.

\section{Two conceptions of blindsight}

Blindsight is a neuropsychological condition defined by residual visual function following partial or complete destruction of primary visual cortex (V1). The most extensively studied patient, GY, was involved in a serious traffic accident aged eight. Consequent trauma led to an intercranial hemorrhage and thence to almost complete degeneration of V1 in his left hemisphere with the exception of a small preserved portion at his occipital pole - a region dedicated to foveal vision (Figure 1; Barbur et al., 1993; Baseler et al., 1999; Bridge et al., 2008). ${ }^{2} \mathrm{GY}$ himself relates both the result (as he conceives it) and its functional consequences: 'I've lost all the vision to my right.' As a boy, 'I literally used to walk into lamp-posts'. ${ }^{3}$

\footnotetext{
${ }^{2}$ Careful mapping of lesions in blindsight is essential. A key criticism of many studies is that preserved abilities may be mediated by spared 'islands' of cortex (Barbur et al., 1993; Morland et al., 2004). Note that the lesion of Weiskrantz's original patient, DB, has never been carefully mapped due to metal clips implanted in his brain.

${ }^{3}$ As interviewed in Christopher Rawlence's PBS NOVA series 'Secrets of the Mind' first aired on 23 Oct. 2001. Currently available at: https://www.youtube.com/watch?v=CTSN9phMZzk [last accessed 23 March 2020].
} 
GY's reported blindness is confirmed clinically by perimetry. For example, Stoerig and Barth (2001; see also Barbur et al., 1993; Barbur et al., 1980) asked GY to indicate if he saw a bright white stimulus roughly the size of a thumbnail held at arm's length when flashed on a dimly illuminated white background. Figure 2 shows the results for GY's right eye. White circles indicating positive responses are seen along the vertical median (and in a cluster at the fovea, corresponding to spared cortex at the occipital pole). Otherwise, stimuli are consistently reported as unseen. Similar results with GY's left eye yield a diagnosis of homonymous hemianopia with about $3-3.5^{\circ}$ degrees of macular sparing. ${ }^{4}$ Weiskrantz likewise reports of his first patient DB, who suffered a lesion in his right primary visual cortex, that 'the [corresponding] defect was absolutely blind; he reported seeing nothing in his left half-field' (2009a: 85).

Despite their avowed unawareness, subjects with blindsight exhibit substantial preserved visual function, including capacities for voluntary discrimination. Indeed, this is the reason for the paradoxical name of their condition: they can see despite their apparent blindness. Such residual discriminative sensitivity is typically established using forced-response and forcedchoice paradigms. In forced-response paradigms, subjects are presented with a single stimulus and must choose from one of two response options (e.g., 'horizontal' or 'vertical'). In forcedchoice tasks, a stimulus is presented in one of $n$ spatial or temporal intervals. For example, in a classic temporal two-interval forced-choice (2ifc) task, a stimulus is presented either in interval $\mathrm{T}_{1}$ or in interval $\mathrm{T}_{2}$, and the subject must respond 'first' or 'second'. As I emphasize below, 2ifc tasks are distinctive in that subjects will naturally select whichever interval corresponds to the highest sensory stimulation, and so are essentially unaffected by response bias (Schulman \&

\footnotetext{
${ }^{4}$ I return to these results and a fuller discussion of Stoerig and Barth's paper below.
} 
Mitchell, 1966; Macmillan \& Creelman, 2005). As a result, above chance performance is perfectly consistent with a subject adopting a highly conservative criterion in relation to each interval considered separately, and so judging of each that it did not contain a stimulus.

Using such tasks, a wide variety of sensitivities have been evinced, in each case in the putative absence of awareness. For instance, blindsight patients have been shown to be capable of discriminating between differently oriented lines and between ' $\mathrm{X}$ 's and 'O's (Weiskrantz et al., 1974 — with DB), between emotional facial expressions (de Gelder et al., 1999; Morris et al., 2001 — with GY), and between different directions of movement (Weiskrantz et al., 1995;

Sahraie et al., 1997; Zeki \& ffytche, 1998 — all with GY). Performance varies across tasks but can be extremely high. In motion direction discrimination, performance can be effectively $100 \%$ in some conditions. Subjects have also been shown to be capable of high levels of performance in forced-choice detection using simple stimuli such as high contrast flashed black circles, again in the absence of reported awareness (Kentridge et al., 1997—with GY; see Figure 3). ${ }^{5}$

\section{The orthodox interpretation}

According to the orthodox interpretation of blindsight, the residual visual function just described can operate in the complete absence of awareness. Weiskrantz describes the discovery of such residual abilities as like 'finding a new continent' (2010: 357), commenting that 'it was immediately obvious that the phenomenon of successful performance without awareness ...

\footnotetext{
${ }^{5}$ Further notable studies of residual performance include: Barbur et al., 1980; Barbur et al., 1994; Blythe et al., 1986; Weiskrantz et al., 1991; King et al., 1996; Azzopardi \& Cowey, 1998; Stoerig et al., 2002; Cowey, 2004; Stoerig, 2006; Persaud et al., 2007. For a meta-analysis of twenty-three further recent studies see Celeghin et al., 2019.
} 
across a startlingly broad range of visual tasks must have a bearing on the neural and philosophical aspects of consciousness' (ibid.). The most obvious apparent implication is that perceptually based intentional engagement with the world can occur without consciousness. Or as Weiskrantz puts it: 'A point that emerges transparently from the phenomenon of blindsight ... is that one cannot draw any conclusions about whether a subject is or is not consciously aware of events simply by studying how good his performance is' (1998b: 228). ${ }^{6}$ Blindsight is also held to have diverse positive lessons. Lamme, for instance, argues that blindsight provides 'substantial evidence in favor of the theory that ... visual awareness is critically dependent on feedback connections to the primary visual cortex' (2001: 209; see also Pascual-Leone \& Walsh, 2001; Tong, 2003; Silvanto et al., 2005; Brogaard, 2011but see Silvanto, 2008; ffytche \& Zeki, 2011). Others take blindsight to reveal 'powerful forms of unconscious processing' (Brown et al., 2019: 765 ) and so to motivate views on which 'consciousness involves higher cognitive processes that depend ... on prefrontal cortex' (LeDoux et al., 2020; Weiskrantz, 1997; Lau \& Rosenthal, 2011; Rosenthal, 2019).

Quite generally, theorists see blindsight as 'central to our understanding of consciousness' (Peters et al., 2016: 1) because it is considered close to unique in involving true absence of awareness despite preserved task performance. This bears emphasis: blindsight has had its enormous impact because — on the present interpretation — it is supposedly quite unlike other cases of degraded vision. Peters et al. contrast visual masking where awareness is said to

\footnotetext{
${ }^{6}$ Likewise, Frith et al: 'blindsight shows that goal-directed behaviour is not a reliable indicator of consciousness' (1999: 107). And Churchland (on the cover of Weiskrantz, 1997): 'The revolutionary blindsight results knocked the stuffing out of the "obvious" assumption that awareness of a signal is necessary for an intentional response to that signal.'
} 
fall off in line with performance (for review see Breitmeyer \& Öğmen, 2006). This view of the significance of blindsight in turn underscores an assumption shared by all these theorists, namely that blindsight involves discriminative responding in the complete absence of awareness. Indeed, blindsight is often simply defined in such terms. ${ }^{7}$

\section{A heterodox interpretation}

The core assumption of the orthodox approach to blindsight is subject to a long-standing, albeit sometimes neglected critique. This critique takes its cue from signal detection theorybased treatments of early research on subliminal perception in neurotypical subjects. Such studies (e.g., Sidis, 1898; Williams, 1938) claimed to find dissociations of performance and awareness by presenting stimuli dimly or at a distance from subjects and then asking them to guess between options as to what was presented. In such studies, subjects would complain that they could not see the stimuli yet go on to guess their identities well above chance. Against the heady claims of early theorists that such findings 'tend to prove the presence within us of a secondary subwaking self that perceives things which the primary waking self is unable to get at' (Sidis, 1898: 171), detection theorists (e.g., Eriksen, 1960) argued for a much simpler explanation: subjects had weak conscious perception of the dim or distant stimulus. This

\footnotetext{
${ }^{7}$ Although some definitions of blindsight talk about the absence of acknowledged awareness, definitions in terms of residual function outside of awareness are commonplace. Thus, Milner writes that blindsight 'refers to any residual visual function, unaccompanied by visual awareness' (1998: 237). Likewise, Ptito and Leh write: 'Blindsight is a visual phenomenon whereby hemianopic patients are able to process visual information in their blind visual field without awareness' (2007: 506). See also Cowey \& Stoerig, 1995; Binsted et al., 2007; Tamietto et al., 2010; Georgy et al., 2016. In the background is the implicit assumption that absence of reported awareness is a sufficient basis for attributing absence of awareness.
} 
perception was sufficient to out-perform chance in a forced-response task, but too weak for subjects to acknowledge as such. ${ }^{8}$

As is now familiar, these ideas can be modelled by associating target stimuli and omnipresent noise with probability density functions, indicating the statistical distribution of sensory responses to target presence (together with noise) and to noise alone (Green \& Swets, 1966). Assuming these distributions are normal and equivariant, the distance between them provides an objective measure of the sensitivity of a perceiver to target presence. In units of their shared standard deviation, this is the ubiquitous statistic $d^{\prime}$. Critically, however, for a perceiver to make a response on any given occasion, they must set a variable decision criterion: a threshold which sensory responses must exceed to merit a corresponding judgment in the relevant task. If such a threshold is conservative, significant underlying sensitivity may not be apparent if performance is assessed in terms of a biased measure such as percent correct (Azzopardi \& Cowey, 1998).

To apply this framework to subliminal perception, consider a task in which a subject must indicate whether a faint line is present or not, and regardless of their answer, guess whether it is oriented horizontally or vertically. Following Macmillan (1986), we can model the decision for this task as in Figure 4. Within such a decision space, reliable orientation judgments are perfectly possible even below a subject's detection criterion, i.e., even on trials when the subject denies that any line is present. In this way, 'signal detection analysis removes much of the mystery from the results ... which are often taken as evidence for subliminal perception'

\footnotetext{
${ }^{8}$ For detailed discussion of this history see Merikle et al., 2001. For an excellent philosophical treatment see Irvine, 2012.
} 
(Holender, 1986: 52). Such results are simply cases where consciously perceived stimuli fail to reach a subject's criterion for detection despite an underlying conscious signal being available.

To apply these ideas to blindsight, consider a more conservative criterion for detection than that depicted in Figure 4. Thus, take Figure 5. In this decision space, the subject will classify almost all signal trials as noise (i.e., respond 'no' if asked whether a stimulus has been presented, and similarly if asked whether they see or are aware of anything). Yet, for all that, the subject may be eminently capable of indicating whether the line is horizontal or vertical if forced to choose due to the availability of a conscious signal.

Earlier, I mentioned that blindsight subjects exhibit high levels of performance in detecting simple stimuli in the absence of reported awareness (e.g., Kentridge et al., 1997). To understand how this fits the model just proposed, note that such performances typically involve two-interval forced-choice (2ifc) detection (e.g., in Kentridge et al., 1997, GY was forced to select which of two temporal intervals a stimulus was presented in). In 2ifc tasks, subjects simply select whichever interval corresponds to the highest sensory stimulation, a strategy which is equivalent to adopting an unbiased criterion. This is perfectly consistent with naturally adopting a highly conservative criterion in relation to each interval considered separately, and so judging of each that it did not contain a stimulus. Because 2ifc tasks are in this way unbiased or 'criterion free', they provide a direct way of assessing underlying sensitivity. In contrast, poor performance in 'yes' or 'no' (yn) detection tasks (as measured by percent correct) may indicate either loss of sensitivity or a strongly biased (e.g., conservative) criterion.

For these reasons, Campion et al., in their wide-ranging critique of early blindsight research, contend: 'Blindsight reduces to no more than the effect of using different decision criteria with degraded vision' (1983: 446) and that 'the stimuli are not unconscious [judged] by 
conventional criteria' (480) — these conventional criteria being ones where it is underlying, objective sensitivity as measured by $d^{\prime}$ or similar which indicate perceptual awareness, not subjective reports. Campion et al. do not insist on such criteria; their point is rather that the patterns of response found in blindsight are insufficient for establishing the reality of performance without awareness and that 'parsimony should lead us to reject it on the present evidence' (446; see also Gazzaniga, 1993; O’Brien \& Opie, 1999; Newell \& Shanks, 2014; Phillips, 2016).

Much evidence has emerged since the early eighties. Today, the near universal consensus is that such evidence conclusively shows that Campion et al. were wrong: blindsight is not merely degraded conscious vision unacknowledged due to conservative response criteria. As I now argue, this is a mistake. QDC is the hypothesis which best fits the evidence. In the next section, I address five major criticisms of QDC. Rebutting them not only shows why theorists have been too quick to abandon QDC but clarifies what really needs explaining about blindsight. This sets the stage for the positive defense of QDC to follow.

\section{Five objections answered}

Five influential criticisms have convinced theorists that QDC is untenable. These criticisms are most commonly levelled at the hypothesis that blindsight is degraded 'normal' vision. It is unclear what this means. What is certainly true is that blindsight does not involve a uniform degradation in visual function. Instead, as Weiskrantz (2009b) discusses, the parametric profile of blindsight comprises a complex and localized pattern of loss, shifted sensitivity, selective sparing and in some cases perhaps even hypersensitivity. However, there is no guarantee that damage to the visual system will produce a uniform decrement in performance. As 
a result, we should not encumber QDC with a commitment to uniformity. Limited sparing and even hypersensitivity are quite consistent with generic degradation. ${ }^{9}$

Indeed, we might anticipate significant differences in vision in blindsight. As Snodgrass et al. argue, 'given the brain damage intrinsic to blindsight, one would expect any residual visual capacities to qualitatively differ' (2009b: 141). In this connection, it is noteworthy that destruction of V1 has significant long-term consequences elsewhere in the visual system. For instance, lesions to V1 lead to drastic and selective degeneration of retinal ganglion cells (as well as dramatic narrowing of the optic tract) (Cowey et al., 2011). And, in the case of GY, diffusion tractography indicates a significant reorganization of his cortical anatomy since childhood, leading to several conspicuous differences compared with neurotypical controls (Bridge et al., 2008). Crucially, however, it does not follow from vision being qualitatively different in blindsight that it is unconscious.

Nonetheless, all five objections remain challenges to QDC, when 'degraded' is understood as allowing for significant departures from 'normal' vision. I address them as such here.

\section{Performance matching}

Weiskrantz emphasizes that 'excellent levels of performance can be matched in the "blind" and sighted hemifields and yet the blindsight subject says he is aware of the latter but not of the former' (2001: 231; Weiskrantz, 2009a: 57-8, 208-16; Lau, 2008). Weiskrantz apparently

\footnotetext{
${ }^{9}$ Compare an army that has been severely depleted but continues to function in the field. Its severe depletion is quite consistent with it performing equally well or better in certain ways. For instance, it may now be able to manoeuvre better and mount more effective guerrilla operations.
} 
takes this to be a decisive objection to QDC. His thought must be that such a pattern of performance indicates a specific deficit of consciousness, over and above the evident loss of visual function, since differences in visual function between the two hemifields have been accounted for by performance matching. However, although extremely influential, this line of reasoning is fallacious. Matched performance in a visual task does not imply that visual function is matched across hemifields. Quite different visual functions may achieve the same end. Asked whether a traffic light indicates stop, a color-blind subject might tell you purely on the basis of position, a visual form agnosic purely on the basis of color. Their performances may match, but their underlying visual function and experiences certainly do not.

Since matched performance across visual fields does not imply sameness of appearance, and since differences in appearance may induce differences in response criterion, matched performance does not imply sameness of response criterion. Differences in reported awareness across fields despite matched sensitivity may thus simply indicate that blindsight subjects adopt a conservative criterion in their 'blind' field, and a more liberal criterion in their sighted field. This explanation is perfectly consistent with QDC. Indeed, the claim that blindsight subjects operate with a highly conservative criterion in their blindfield is a key feature of the view.

There is every reason to take this account seriously. It is independently well-attested that neurotypical subjects can exhibit large differences in reported awareness despite matched task performance due to differences in what Kahneman terms 'criterion content' (1968: 410). ${ }^{10}$

\footnotetext{
${ }^{10}$ Kahneman defines criterion content as 'the code that a subject uses in mapping his private experience onto responses to the experimenter's question' (1968: 410). That is, criterion contents refer to how stimuli appear to a subject and which stimulus aspects subjects draw on in making their judgements. Differences in criterion contents can lead to differences in response criterion but the two notions should be sharply distinguished.
} 
Consider studies of visual masking in which subjects must detect or identify masked targets. For a given target/mask pairing, masking magnitude as measured by performance is a complex function of stimulus onset asynchrony (SOA) between target and mask (Figure 6). As Kahneman discusses, many different criterion contents may lie behind successful performance at different SOAs. Mostly obviously, subjects may detect the target because they see it as a clearly defined object, with sharp and definite contour. But they may equally detect it in less obvious ways, for instance by noticing that the mask differs in brightness or contrast or undergoes apparent expansion. ${ }^{11}$ Such contents may allow subjects to perform as well as if they had distinctly seen the target. Yet when such subjects are asked if they saw the target they may well say 'no'. For naturally, the 'motion [or dimming etc.] of the masking figures is ignored, since the observer confines his report to the presence or absence of the central object' (Kahneman, 1968: 412). In psychophysical terms, such subjects will adopt highly conservative criteria for 'target seeing' despite their excellent detection performance.

This pattern of performance is effectively rediscovered in Lau and Passingham's (2006) studies of so-called 'relative blindsight'. Lau and Passingham exploit the characteristic shape of the metacontrast masking function (Figure 6), to identify two SOAs at which task performance is matched-for their stimuli, 33 and 104ms. They then show that reported awareness differs across these two SOAs and argue that this evidences that the 'subjective level of consciousness can differ in the absence of a difference of performance levels' (ibid: 18763) — a phenomenon they dub 'relative blindsight'. However, a simpler hypothesis is that criterion contents differ across

\footnotetext{
${ }^{11}$ Kahneman relies principally on Sperling, 1965. For updated treatments of visual masking and criterion contents see Bachmann and Francis, 2013, esp. p.10ff, and the highly pertinent and systematic analysis in Koster et al., 2020 Whilst details differ, the salient points remain the same.
} 
the two SOAs in question, and consequently subjects adopt different response criteria. ${ }^{12}$ This hypothesis is supported by Jannati and Di Lollo (2012) who point out that Lau and Passingham's diamond and square targets (Figure 7(a)) generate quite different percepts at the two masking SOAs. At an SOA of 33ms, target and mask fuse, generating a blended percept as of a single object (Figure 7(b)). In contrast, at an SOA of 104ms, target and mask are seen as distinct objects (Figure 7(c)). These percepts both allow for target identification, since one can tell from the blended percept what the target is. However, subjects are understandably more reluctant to report seeing the target in this condition. This does not reflect different 'levels of consciousness,' but simply different percepts. In Kahneman's terms, a difference in criterion content naturally leads subjects to adopt a more conservative criterion for target seeing in the shorter SOA condition. ${ }^{13}$

Returning to blindsight proper, QDC can explain performance matching across fields if (a) criterion contents in the blindfield differ from those in the sighted field, and (b) blindfield contents elicit a naturally conservative criterion in respect of reports of seeing or awareness. I provide evidence for both contentions below.

\section{Dissociations between 2 ifc and yn sensitivity}

\footnotetext{
${ }^{12}$ Differences in criterion contents despite matched sensitivity would also seem to be the simplest understanding of the differences in confidence ratings between high and low positive evidence conditions exploited in Samaha et al., 2016 (see also Zylberberg et al., 2012; Koizumi et al., 2015).

${ }^{13}$ Peters et al. (2016; citing Maniscalco \& Lau, 2010, and Maniscalco et al., 2016) suggest that the phenomenon of relative blindsight can be replicated in a different paradigm with stimuli for which criterion contents are better matched. For the more fundamental concern that relative blindsight reflects differences in response bias as opposed to awareness see Baldson \& Azzopardi, 2015, and Peters et al., 2016 for a reply. See also Lloyd et al. 2013.
} 
A rightly celebrated finding, often taken to show that blindsight is not simply degraded conscious vision (e.g., Lamme, 2001: 211; Weiskrantz, 2009a: 57-8; Heeks \& Azzopardi, 2015; LeDoux et al., 2020) comes from psychophysical work by Azzopardi and Cowey (1997, 1998; replicated in macaques by Yoshida \& Isa, 2015). According to the standard gloss on their results, Azzopardi and Cowey show that 2ifc sensitivity in blindsight exceeds yn detection sensitivity (even once necessary mathematical corrections have been applied). ${ }^{14}$ This would mean that blindsight cannot simply be explained in terms of qualitatively degraded conscious vision unreported due to conservative response criteria. Instead, it would seem to suggest that signal is available for $2 \mathrm{ifc}$ responding in blindsight which is unavailable to yn detection. This appears strongly consistent with a picture on which unconscious information is available to guide certain kinds of 'forced' responses in blindsight, despite being unavailable for conscious detection (Weiskrantz, 2009a: 58; Lau, 2008: 250). The finding so-interpreted, further underscores the centrality of blindsight in consciousness research since this dissociation is not found in neurotypical observers (Heeks \& Azzopardi, 2015; Balsdon \& Azzopardi, 2015).

\footnotetext{
${ }^{14}$ The background assumption here is that 2ifc $d^{\prime}$ is related to yn $d^{\prime}$ by a simple mathematical formula: $d^{\prime}{ }_{2 i f c}=$ $\sqrt{2} d^{\prime}{ }_{y n}$ (e.g., Macmillan \& Creelman 2005: 168-70). Thus, Azzopardi and Cowey show that $d^{\prime}{ }_{2 i f c}>\sqrt{2 d^{\prime}}{ }_{y n}$ for GY in relation to static stimuli, whereas the standard square root rule holds in their neurotypical control group. However, we should be cautious in assuming that this rule holds in general. Indeed, the first work investigating the relationship between yn and 2ifc sensitivity found a clear dissociation in estimates of $d^{\prime}$ (Nachmias, 1981; see Cowey, 2004: 586). Moreover, Yeshurun et al. (2008) in reviewing the literature find "little reason" to accept the rule, and themselves provide evidence against it for their particular stimuli and design. In consequence, the general pattern of relations between 2 ifc and yn $d^{\prime}$ remains an important issue for further investigation, with potential bearing on blindsight.
} 
This familiar gloss on Azzopardi and Cowey's findings is misleading for two reasons, however. First, it neglects that in one respect their findings straight-forwardly support QDC. Second, it overlooks a quite different interpretation of their results with static stimuli on which a single conscious signal underlies both 2ifc and yn performance-an interpretation fully consistent with QDC.

On the first point, note that Azzopardi and Cowey show that GY does indeed adopt a highly conservative response criterion in yn responding $(c \approx 2)$ as compared to an essentially unbiased criterion $(c \approx 0)$ in 2 ifc and yes or guess responding. ${ }^{15}$ They comment that differences 'of this magnitude could easily produce significant dissociations of performance when measured with percent correct if sensitivity was constant in the two tests, provided $d^{\prime}$ is greater than about 1' (1998: 298). This is of course entirely in line with QDC. Furthermore, Azzopardi and Cowey go on to show that 2ifc and yn sensitivity are perfectly correlated in GY for moving stimuli. Again, this is just as QDC would predict. As they comment: in relation to such stimuli, blindsight appears to be 'nothing more than patient's use of consistently different response criteria during clinical [yn] and forced-choice [2ifc] testing' (1998: 302). In this respect, then, blindsight is no different to other cases of degraded vision such as masking, except for the relative extremity of the criterion. ${ }^{16}$

The striking apparent dissociation of 2ifc and yn sensitivity specifically concerns static stimuli. Here, and in contrast to control subjects, GY appears to exhibit significantly greater

\footnotetext{
${ }^{15}$ In a yes or guess task, the subject must answer 'yes' if they see a stimulus, and otherwise guess whether one was presented. Such tasks seek to minimize response bias (or possibly to induce response bias in an associated yn task).

16 This said, in the light of the points made in Footnote 14, we should be cautious about assuming that 2 ifc and yn sensitivity obey the standard square root rule in relation to any given type of masking or stimulus.
} 
sensitivity in $2 \mathrm{ifc}$ responding as compared to yn responding. Does this show that blindsight for static stimuli is inconsistent with QDC? It does not. In later work, Azzopardi and Cowey (2001a) suggest an elegant explanation of what may underlie the surprising difference in sensitivity which is wholly consistent with a single conscious process account. ${ }^{17}$ This explanation notes that calculations of sensitivity presume that a subject adopts a stable criterion across trials (Treisman \& Williams, 1984). If this assumption is violated, then criterion instability will increase the apparent variance of signal and noise distributions, thereby giving the appearance of lowered sensitivity (Figure 8). This will distinctively affect yn responding since, as noted above, 2ifc tasks are effectively criterion free (subjects always adopt the same unbiased criterion) and so should not exhibit any significant criterion variance. Azzopardi and Cowey go on to provide evidence from sequential dependencies in GY's responding which are consistent with precisely this picture (see further below, Footnote 35).

The upshots here are twofold. First, and foremost, we have clear psychophysical evidence that blindsight involves the adoption of highly conservative criteria in detection tasks. This is a central feature of QDC and one I return to throughout what follows. Second, GY's performance in relation to static stimuli can be understood as a result of criterion instability with respect to such stimuli. Below, I explain how QDC can explain both conservativeness and selective criterion instability in blindsight.

\section{Exclusion paradigms}

\footnotetext{
17 This does not seem to be Azzopardi's own view, however. Elsewhere, citing his earlier work, he writes: 'performance can be dissociated from awareness following neurological damage' (Heeks \& Azzopardi, 2015: 75).
} 
A third notable objection to QDC concerns exclusion behavior. Specifically, Persaud and Cowey (2008; Persaud \& McLeod, 2014) show that GY makes systematic errors in an exclusion task when stimuli are presented in his blindfield. This is claimed to be straightforwardly inconsistent with QDC. In their task, GY was asked to report where a square grating did not appear in a spatial 2ifc design in which it could appear either in the upper or lower quadrant of his blind or sighted field at a variety of contrast levels. In his sighted field, as contrast increased, GY's performance steadily improved under both inclusion and exclusion instructions, as we would expect. However, in his blindfield, as contrast increased, GY increasingly made errors under exclusion instructions. Thus, at high contrast he (wrongly) chose the target's actual location $62 \%$ of time under exclusion instructions versus $64 \%$ with inclusion instructions. Persaud and Cowey claim that failure to exclude shows that the relevant information 'could not have could not have been processed consciously because [otherwise it] would have been used to make correct exclusion responses' (1051). They also contend that their method 'clearly circumvents the problems with subjective reports' (1054) and that their results are 'not a mere ... artefact of response biases' (1050) since they do 'not rely on subjective reports' (ibid).

Both of these claims are problematic, however, as I now explain. GY's significantly elevated exclusion error rate shows that he was able to discriminate target present and target absent quadrants at high contrast. However, we cannot infer from his failure to exclude that he was not consciously aware of a difference in appearance between quadrants, let alone that his sensitivity is 'solely subconscious in the blindfield' (1054). For, contra Persaud and Cowey, exclusion is a task which requires a criterion-based response strategy (Snodgrass, 2002). Consequently, it is very much subject to concerns about response biases. To see this, suppose that GY sets the following standard rule in the normal inclusion version of the 2ifc task: respond 
to whichever interval presents the strongest signal. Now suppose that under exclusion instructions GY adopts the rule that he will respond as before unless he sees the stimulus - in which case he will select the opposite interval. Since his criterion for 'seeing' is highly conservative, adopting this perfectly natural strategy will mean that GY performs much the same in exclusion and inclusion tasks, leading to a significantly elevated error rate (i.e., increase in responding to the target's actual location) under exclusion instructions. The upshot is that GY's exclusion behaviour is wholly consistent with QDC given previous commitments to conservative responding in his blindfield. This is illustrated in Figure 9. The similarity with Figure 5 suggests that QDC should predict significant failures to exclude under exclusion instructions.

In this context, a further point is worth making regarding exclusion tasks more generally. Such tasks are widely regarded as demonstrating a distinction between conscious and unconscious processing (e.g., Debner \& Jacoby, 1994; Persaud \& McLeod, 2007; though see Fisk \& Haase, 2007, 2013). However, it is obscure what consistent view of the functional role of unconscious processing would generate the observed pattern of data in exclusion tasks. Consider, for instance, that the responses in Persaud and Cowey's task are entirely voluntary choices—not speeded movements, more plausibly guided by unconscious automatic processing. Yet since information is available for such slow, considered choice behavior, it is puzzling why one should predict a failure of exclusion. If the information is available for voluntary choice, why is it that it cannot be used flexibly? Snodgrass' decision theoretic model provides an answer here. Simply noting that the information is unconscious does not. Consider, further, that in Persaud and McLeod's (2008) exclusion task with neurotypical subjects, failure to exclude involves subjects reporting the identities of the stimuli which are in fact presented: a performance which, as Newell and Shanks point out, would 'normally be taken as direct evidence of conscious, not 
unconscious, processing' (2014: 51). Here too then the link between failure to exclude and lack of awareness is opaque.

\section{Functional profile}

A related and broader criticism of QDC is that it cannot account for the alleged functional profile of blindsight. Specifically, it is widely held that in blindsight subjects, 'unseen stimuli never spontaneously induce behaviour, even after extensive training (although this does happen in monkeys)' and that 'blindsight capacities only become evident in forced laboratory settings' (Lamme, 2006: 496; Dehaene \& Naccache, 2001: 11; Weiskrantz, 1997). For Lamme and many others, this lack of unprompted, spontaneous action indicates that blindsight is genuinely unconscious, as opposed to merely unreported, perception. The idea here harks back to Marcel's notorious remark that blindsight 'patients will make no spontaneous attempt to grasp a glass of water in their blind field even when thirsty' (1986: 41; Morsella, 2005). Given that blindsight patients lack form and object perception (see below), Marcel's example is fanciful. But the background contention linking lack of spontaneity with lack of consciousness needs taking seriously. Nonetheless, there are three good reasons to reject a functional profile argument for the absence of awareness in blindsight.

First, voluntary responses to stimuli, just like verbal reports, are the joint upshot of perceptual sensitivity and response criterion. Thus, the fact that a subject fails to respond to a stimulus may simply reflect their conservative response criterion in relation to the stimulus. ${ }^{18}$ To

\footnotetext{
${ }^{18}$ This is an application of the very general point (Snodgrass \& Shevrin, 2006: §17; Snodgrass, 2002; see also Block, 2001, 2005) that putative qualitative differences between unconscious and conscious processes may simply reflect the application of a response strategy within conscious perception.
} 
use Marcel's example: a thirsty person will not spontaneously attempt to grasp a glass of water in front of them if they do not think that a glass is there. Since we already know that blindsighted subjects adopt conservative criteria for verbal and manual reports, it should hardly be a surprise if they also adopt such criteria for other actions. Of course, outside of the laboratory, most blindsighted subjects have an intact hemifield with vastly superior vision to rely on for sating their thirst. This is not so for bilateral patient, TN, reported by de Gelder et al. (2008). However, setting controversy about the case aside, TN's performance (walking unaided down a corridor whilst navigating various obstacles) would on the face of it seem to be a striking example of spontaneous, voluntary behaviour in blindsight.

Second, there is evidence that not all function in blindsight requires cueing. For instance, Stoerig reports a detection paradigm in which 'cues did not enhance, let alone enable blindsight in [her blindsighted] participants' (2010: 8). Since above chance detection was nonetheless in evidence, she concludes: 'Stimuli presented to regions of absolute cortical blindness [sic] can thus prompt, rather than merely modulate, non-reflexive responses.' (ibid.) This is just as we would expect if lack of spontaneity were due to conservative response criteria. For, as I emphasise in the next section, this hypothesis predicts the existence of circumstances where such a criterion is lowered.

Third, it is in any case obscure why spontaneous action should be regarded as a functional signature of consciousness. According to Bayne, the (alleged) 'fact that blindfield content is not spontaneously employed by the subject suggests that it is not accessible to her as such — that is, at the personal level.' (2013: 171) However, much of our conscious experience is not spontaneously employed in action. Our sensory experience is full of features to which we 
give little heed or notice: background noises such as the hum of a computer fan, or the rumble of distant traffic, or miscellaneous visual phenomena such as shadows, highlights and floaters.

Relatedly, Dretske connects the alleged inability of blindsighted subjects 'to exploit [perception] to initiate spontaneous behaviour' (2006: 167) with their lacking information which can provide a (justifying) reason for action (see further references therein). However, the information in blindsight is clearly available to inform voluntary action-for the 'pursuance of future ends and the choice of means for their attainment' as James (1890: 8) famously puts it. Even if the blindsighted subject's decisions are typically elicited by a cue, such cues do not cause them to make an involuntary twitch, nor do they automatically modulate actions already in progress (as apparently in Pisella et al., 2000). Rather, cues prompt subjects to voluntarily select an interval or report a stimulus dimension. The availability of information for the selection and execution of voluntary action strongly suggests that the information does constitute personallevel reasons (even if reasons which the subject themselves will not normally offer up under questioning).

In short, whilst it is true that stimuli in the blindfield rarely elicit spontaneous responses, this is to be expected given their conservative response criteria for report, it is not universally true, and in any case the connection between spontaneous (as opposed to voluntary) action and consciousness is unclear.

\section{Metacognition}

Finally, it might be suggested that evidence of suboptimal metacognition in blindsight weighs against QDC and in favor of an orthodox interpretation. Most notably, Persaud et al. (2007) claim that post-decision wagering constitutes an objective measure of awareness and go 
on to report that GY wagered optimally on his decisions only $48 \%$ of the time despite making $70 \%$ correct detections in a yn detection task. Persaud et al. (2011) further report that GY exhibited metacognitive inferiority in his blind as compared to his sighted field, even when his type 1 sensitivity was matched across fields. These results might understandably be seen as indicating that GY's type 1 sensitivity was not available to awareness.

Drawing such an inference is problematic for several reasons, however. First, the measures of metacognitive sensitivity employed in both studies do not deconfound type 2 sensitivity from type 2 bias (Maniscalco \& Lau, 2012: 422). ${ }^{19}$ As a result, GY's suboptimal wagering may simply reflect loss aversion under uncertainty as opposed to lack of awareness (Schurger \& Sher, 2008). This would be entirely in line with QDC. Second, given their payoff matrixes, both wagering tasks have a (weakly) dominant strategy which is independent of metacognitive access. The optimal strategy is always to bet 'high' in Persaud et al. 2007, and always to bet on one's type 1 responses in Persaud et al. 2011. The upshot is that neither task provides direct evidence of metacognitive awareness. After all, optimal performance is consistent with its complete absence (Clifford et al., 2008; Konstantinidis \& Shanks, 2014).

Third, even were these issues to be addressed, it is unclear how to interpret a true lack of metacognitive sensitivity. Seth (2008), for instance, argues that post-decision wagering measures 'metacognitive content' as opposed to perceptual consciousness per se. And Maniscalco and Lau propose 'a double dissociation between type 2 sensitivity and the contents of awareness' (2012: 429). Part of their reason here is that GY appears to exhibit above-chance metacognitive

\footnotetext{
${ }^{19}$ For much broader concerns about the objectivity of existing measures of metacognition see Shekhar and Rahnev, 2020.
} 
sensitivity in his blindfield in Persaud et al. 2011 (even if it is inferior to his sighted field) despite his alleged lack of awareness. Were it not for the points above, this might in fact seem evidence in favor of QDC (Overgaard, 2012: 611).

Finally, discussing their finding that metacognitive sensitivity is suboptimal in neurotypical subjects, Maniscalco and Lau suggest four possible explanations. One of these posits a putative “"unconscious” processing stream' (2012: 427), an explanation consistent with the orthodox view of blindsight. However, in their view, sub-optimality might equally reflect: (a) decay of information following the type 1 decision; (b) accrual of additional noise following the type 1 decision; and/or (c) differential noise in type 1 and type 2 decision processes, specifically, differential variability in criterion setting. Explanations (a)-(c) are quite consistent with QDC. Consequently, even were there to be a clear demonstration of suboptimal objective metacognitive sensitivity in blindsight, this would not provide direct evidence against QDCcertainly not without very significant additional theoretical assumptions concerning the relation between metacognition and consciousness.

\section{Summary}

We have now considered five objections to QDC. In each case, QDC has been shown wholly consistent with the psychophysical data. ${ }^{20}$ Our discussion has, however, highlighted two

\footnotetext{
${ }^{20}$ What of neurological data? Whilst a fuller understanding of the neural mechanisms subserving residual function in blindsight will surely be of critical value in any complete understanding of the condition, extant evidence does not resolve our present controversy. This is because there remains scant agreement concerning the neural correlates of consciousness (compare and contrast: Dehaene \& Naccache, 2001; Lau \& Rosenthal, 2011; Lamme, 2010; Boly et al., 2017) and large methodological obstacles to resolving the issue (e.g., Block, 2001, 2005; Phillips, 2018). Consequently, it is not possible at this time to determine whether, for instance, evidence of hypoactivation in GY's
} 
desiderata on any adequate account of blindsight: to explain why subjects set highly conservative criteria in their blindfield despite their significant residual sensitivity; and to explain why these criteria are unstable in relation to static stimuli. I now turn to the positive case for QDC, showing how these explanatory burdens can be discharged.

\section{The positive case for QDC}

QDC is consistent with the psychophysical data. But is there positive discriminating evidence in its favor? I now argue that QDC makes a series of distinctive predictions borne out by the available evidence. Furthermore, QDC has the resources to discharge the explanatory burdens just identified.

Before considering this evidence, it is important to appreciate that QDC has claim to be the default interpretation of blindsight on grounds of simplicity and explanatory breadth. This is because QDC appeals only to constructs already firmly established as necessary for any adequate account of visually based behavior, namely a conscious signal available for intentional discrimination in combination with a variable response criterion. In contrast, the orthodox, inflationary interpretation of blindsight in effect proposes two signals: one conscious, the other unconscious, both contributing to performance in different ways in different circumstances. Against this, the proponent of QDC should insist that if QDC can explain blindsight in terms of already well-established resources (viz. a single-conscious signal available for sensory discrimination) it should be favored. As Snodgrass puts it in a different context: 'A consciousperception-only model is the null hypothesis and, if viable, is more parsimonious because it

left PFC (Persaud et al., 2011) indicates a deficit of consciousness or instead a lack of criterion-based, postperceptual cognition. 
postulates only one rather than two perceptual processes.' (2002: 556; Snodgrass et al., 2009a)

Here we appeal to a quite general scientific precept that good scientific theories are not motleys but 'consist of just one problem-solving strategy... applied to a wide range of problems.'

(Kitcher, 1982: 47) Of course, null hypotheses should be rejected if they cannot account for the data or fail to represent a fruitful research strategy. QDC, however, is an extremely promising research strategy.

In this context, it might also be objected that the case for QDC assumes that a conservative criterion implies a decisional or response bias. If, however, we distinguish between perceptual and response biases (Witt et al., 2015; Peters et al., 2016), then we might instead construe blindsight as a perceptual criterion effect, a view consistent with the orthodox understanding of blindsight as a matter of unconscious (i.e., below perceptual criterion) perception.

It is a substantive question whether we should in fact acknowledge a distinction between perceptual and response criteria. ${ }^{21}$ For present purposes, however, the critical issue is whether

\footnotetext{
${ }^{21}$ I am sceptical. First, the distinction is no part of traditional detection theory (see, e.g., Green \& Swets, 1966: 1189). Indeed, the view that whether a stimulus is seen is a matter of it reaching a perceptual criterion harks back to threshold models of perception which, as Macmillan (1986: 38) puts it, "have been eroded by psychophysical progress". Second, the natural way of acknowledging the existence of 'perceptual decision making' is not to introduce perceptual criteria, but rather to recognize that detection theory can be used to model perceptual systems as well as perceivers. So modelled, perceptual systems can be considered as decision makers with response criteria. However, these criteria should be kept quite separate from the response criteria of subjects. Finally, whilst recent modelling work by Witt et al. (2015) appears to make a strong case for distinguishing perceptual and response criteria, it is not clear that their model applies to behavioral (as opposed to simulated) data (cf. Knotts \& Shams, 2016). Moreover, to distinguish perceptual and response bias within their model of the Müller-Lyer illusion, Witt et
} 
introducing such a distinction undermines the argument for QDC. In my view, it does no such thing. Distinguishing perceptual and response criteria introduces a rival hypothesis which deserves development and consideration. However, as things stand, QDC should remain our preferred account of blindsight for two reasons. First, as already emphasized, QDC offers an especially parsimonious account of the patterns of subjective report and performance found in blindsight and which are typically held to support an orthodox account. This is because it can explain these patterns exclusively in terms of a degraded perceptual signal combined with a conservative response criterion. In contrast, whereas an account in terms of perceptual bias may avoid postulating two perceptual signals, it nonetheless invokes two distinct kinds of cognitive processes in appealing to response and perceptual criteria. Ceteris paribus, parsimony again favors QDC. ${ }^{22}$ Second, the positive evidence in favor of QDC offered in this section is strongly suggestive that blindsight specifically involves shifts of response criterion. In particular, as I now argue, blindsighted subjects acknowledge awareness under variations of instruction, response options, and motivation. Such manipulations are far more naturally understood as targeting response as opposed to perceptual criteria.

al. suppose that the detection theoretic decision axis represents perceived line length. However, traditionally the decision axis is taken to represent a parameter such as ratio of hits to misses or expected value (see Lages \& Treisman, 1998 on the difference between signal detection theory and sensory memory theory). If the decision axis is understood in this way, the distinction between perceptual and response bias cannot be drawn.

${ }^{22}$ Of course, if one considers there to be strong independent grounds for marking a distinction between perceptual and response criteria, then appealing to variation in perceptual criteria to account for blindsight will not be unparsimonious since it will exploit only already acknowledged resources. This, however, returns us to the question of whether there are good reasons to introduce such a distinction. See discussion in the previous note. 


\section{Varying the criterion}

The canonical interpretation of blindsight considers destruction of V1 to abolish phenomenal awareness. On this interpretation, we should not ever expect blindsight subjects to report awareness, let alone consciously seeing stimuli in their blindfield. Quite the contrary. In contrast, QDC claims that degraded phenomenal awareness is present wherever there is preserved discriminative function. It is unacknowledged as opposed to absent. Detection theory traditionally regards response criteria as flexible and, in principle, under the voluntary control of subjects (Morgan et al., 2012; Macmillan, 1986). Moreover, they are notoriously subject to manipulation and influence. As Draine and Greenwald write in relation to visual masking: 'It is well known that ... the boundary between judged presence and absence of a stimulus can be influenced by instructional or motivational variations.' (1998: 287) Thus, a first distinctive prediction of QDC is that blindsight subjects will acknowledge visual awareness under pertinent manipulations of their response criterion. A second, related prediction is that performance will correlate with reported awareness given a fixed criterion. This is because QDC postulates a single conscious signal subserving all performance. Thus, holding fixed a subject's response criterion, strengthening a signal will improve performance and increase the likelihood of report and vice-versa. In contrast, the orthodox interpretation of blindsight which postulates a distinct unconscious signal, predicts neither reported awareness nor any simple correlation between reports and performance (since it postulates an entirely unreportable signal). In both cases, the evidence tells in favor of QDC.

First, consider evidence of acknowledged awareness due to variation in instruction. Stoerig and Barth (2001) presented GY with a bright white stimulus at various locations in his blindfield. In their first condition, the instruction was to 'press when you see something'. We 
saw the results above in Figure 2, for convenience reproduced here as Figure 10(a). They appear to illustrate the traditional view of blindsight: GY exhibits an almost complete absence of positive response, except for a few instances at the center of his vision corresponding to the cortical sparing at the occipital pole. However, in a second condition with the same stimuli, Stoerig and Barth altered the instruction to: 'press when you are aware of something'. The results can be seen in Figure 10(b). A dramatic change is observed. Asked this second question, GY acknowledges awareness in substantial regions of his 'blind' field. Similarly, Weiskrantz reports a patient, EY, who 'showed a typical dense ... hemianopia with perimetry when he was asked to report when he saw the light coming into his field — he was densely blind by this criterion.' Yet: 'If he was asked to report merely when he was "aware" of something coming into his field, the fields were practically full.' (1980: 378)

QDC has a straightforward explanation of this: blindsight subjects are inclined to adopt a more conservative threshold for reporting 'seeing' as compared to mere 'awareness'. Stoerig and Barth's change of instruction thus induces a criterion shift. Reasons for this shift will be made clear shortly.

Weiskrantz and other defenders of a traditional view of blindsight of course appreciate that awareness is sometimes reported in the blindfield. Weiskrantz accounts for this by proposing that there are in fact two types (or modes) of blindsight: type I and type II (1998a). ${ }^{23}$ Type II blindsight is said to involve feelings or awareness but never visual qualia or seeing. Plainly this

\footnotetext{
${ }^{23}$ It is a surprisingly common confusion to think that this distinction refers to two types of patient. It does not. The distinction rather adverts to the fact that within subjects above chance performance is sometimes accompanied by reported awareness, sometimes not.
} 
move increases the gulf in economy between QDC and the traditional blindsight story-ffytche and Zeki (2011: 255) understandably complain of 'a changing of the goal posts'. ${ }^{24}$ Moreover, as Eysenck and Keane put it, type II blindsight 'sounds suspiciously like residual conscious vision' (2010: 64). Yet, even setting these concerns aside, Weiskrantz's type I/type II view continues to make a contrary prediction to QDC, for it maintains that blindsight never involves conscious seeing or visual qualia — blindsight is always type I or type II. In contrast, QDC proposes that blindsight always involves conscious seeing but that its subjective classification is subject to criterion effects. A clear prediction is that genuine seeing will be reported by blindsight subjects in the right situations.

Scrutiny of the literature confirms this prediction. For instance, as noted above, Kentridge et al. (1997) asked GY to detect a black $1^{\circ}$ diameter circle, flashed three times over a $600 \mathrm{msec}$ interval with an onset of $96 \mathrm{msec}$ in various locations. In one condition, GY was informed of the locations in which stimuli would be flashed. In this condition, he was $98 \%$ and $97 \%$ successful on trials in locations at $9^{\circ}$ and $12^{\circ}$ along his horizontal meridian. He also reported awareness on $65 \%$ and $62 \%$ of occasions. In his words, his discriminations were, he felt 'mostly right', he was 'mostly aware' of targets, he was 'seeing a lot' (1997: 194-5). This example is striking because the stimuli are the same across conditions of reported awareness and unawareness. But with some stimuli, GY habitually reports seeing. Thus, Barbur et al. (1993) report that in their stimulus conditions GY ‘demonstrated clear, conscious awareness of motion’ (1294). That is: 'Whether tested subjectively — through a verbal report or objectively — through discrimination,

\footnotetext{
${ }^{24}$ Interestingly, they also indicate that GY originally described his experience in visual terms but has 'only more recently ... used the term "feeling" to qualify his visual experience' (2011: 254). As discussed below, GY is not a naïve subject.
} 
the subject gave every sign of having seen and having been consciously aware of what he had seen. Thus, when stimulated with a moving stimulus, [GY] verbally reported seeing movement.' (1295) Understandably they note that, at least for their stimuli, 'the term blindsight does not describe [GY's] residual visual capacity correctly' (ibid.) Whilst not representative, these reports show that GY does sometimes report conscious vision, sometimes even routinely. It would appear wrong to claim that blindsight never involves visual qualia. ${ }^{25}$

A second place to look for acknowledgement of awareness in blindsight is under variation in response options. Several studies have now explored this issue, contrasting the dichotomous (seen/not seen) response options of traditional blindsight studies with a graded, four-point Perceptual Awareness Scale (PAS) comprising: no experience, weak experience, almost clear experience, and clear experience (Ramsøy \& Overgaard, 2004). Overgaard et al. (2008) studied a blindsighted woman, GR, using the PAS and found that, whereas she reported no awareness using a traditional yn measure (and so met traditional diagnostic criteria for type I blindsight), using the PAS scale, 'her blindsight seemingly "disappeared" in the sense that ... [a]ll correctness above chance seemed related to vague yet conscious vision' (Overgaard, 2011: 477).

Doubts might be raised as to whether GR's performance relied on spared cortex. However, a very similar finding is seen in patient SL whose lesion has been carefully mapped (Celeghin et al., 2015). Specifically, in Mazzi et al. (2016), SL performed a series of

\footnotetext{
${ }^{25}$ Even Persaud and Lau's attempt to establish the absence of qualia in GY (criticized in Phillips, 2016: 440f.) evidences that GY does at least sometimes experience visual qualia, though as he puts it 'Only very rarely ... on very easy trials, when the stimulus is very bright' (2008: 1048).
} 
discrimination tasks along various stimulus dimensions-orientation, color, contrast, and apparent and real motion. In Experiment 1, SL reported awareness on a trial-by-trial basis using a binary (seen/guessed) response measure. In Experiment 2, she reported awareness on a fourlevel scale. It transpired that guessed responses in Experiment 1 corresponded not only to no experience but also to weak experience responses in Experiment 2. Moreover, when no experience was reported, there was no evidence of above-chance performance in the discrimination task. These results strongly support the prediction of QDC that the 'threshold to acknowledge conscious vision can change depending on the way awareness [is] assessed' (Mazzi et al., 2017: 104). Mazzi et al.'s results also support the second prediction of QDC, namely that awareness will, all else equal, correlate with performance. Other studies of blindsight further confirm this. For instance, Morland et al. examined seven hemianopes, including GY. Only three had any ability to discriminate the moving stimuli used. All three reported awareness. In contrast, the other five patients reported no awareness at all (2004: 206; see also Phillips, 2020, on Garric et al., 2019).

A study of motion discrimination by Zeki and ffytche (1998) further evinces a clear correlation between reported awareness and performance. It also provides a suggestive example of reported awareness under variation in response criteria. Zeki and ffytche asked GY to indicate in which direction a stimulus was moving at a variety of contrasts, as well to report awareness on a trial-by-trial basis. As the results shown in Figure 11 indicate, GY makes a significant proportion of aware responses corroborating the first prediction of QDC. We can also see a clear correlation between reported awareness and performance. Indeed, the resemblance of most blocks to familiar vision (or blindness) is striking. That is, in most blocks, GY either reports no awareness and performs at chance, or reports awareness and correspondingly performs above 
chance. Performance which might be considered traditional blindsight is confined to a cluster of blocks in the lower right of the graph in which GY reports no awareness but still performs significantly above chance. Considering this overall pattern of data, one might postulate two modes or types of blindsight — one corresponding to these 'no awareness' blocks (type I) and one to the 'awareness' blocks (type II). However, a far simpler hypothesis is that GY has degraded conscious vision, but a tendency to operate with a conservative criterion in certain circumstances. Minded of the tedium of performing many hundreds of psychophysical trials, Azzopardi and Cowey (1998) propose that this conservative responding results from boredom or tiredness - he simply loses motivation and gives up. Kentridge (2015) instead suggests that GY may have been attempting to read the expectations of the experimenters in the different blocksa point I return to below. Either way, QDC offers an elegant account of Zeki and ffytche's data.

In this section we have seen several distinctive predictions of QDC borne out. First, we find both reported awareness and sight, under variations in instruction, response options, and (arguably) motivation. The canonical interpretation of blindsight struggles to accommodate such reports. Second, we find an overall pattern of correlation between reported awareness and performance. Again, this is fully consistent with QDC.

\section{What is it like to have blindsight?}

I now turn to a fundamental question which QDC prompts: what is it like to have blindsight? According to QDC, there is phenomenology whenever there is performance in blindsight. What is unclear, however, is what phenomenal contents subserve residual performance, and how these compare to neurotypical vision. To answer these questions, we must consider behavioural evidence alongside first-person reports. In combination, a picture emerges on which blindsight involves radically altered and etiolated but nonetheless conscious vision. 
This evidence in turn strengthens the case for QDC since it provides the materials for explaining the conservative and selectively unstable response criteria encountered above.

I begin with behavioural data. First, note that residual vision in blindsight is 'severely impoverished' (Cowey, 2004: 588; Beckers \& Zeki, 1995: 56) both quantitatively and qualitatively. Wavelength sensitivity is reduced by an order of magnitude as compared to neurotypical vision (Stoerig \& Cowey, 1992), orientation sensitivity is similarly impaired (Morland et al., 1996). And contrast sensitivity is reduced by two orders of magnitude (Barbur et al., 1980; Barbur et al., 1994), such that 'even a seeing subject [sic] would be clinically classed as blind' (Cowey, 2004: 588).

Turning to qualitative losses, note that many of the visual capacities of blindsight are greatly exaggerated in the popular scientific imagination. As mentioned above, commentators (following Marcel, 1986) are fond of pointing out that a thirsty blindsight patient would not spontaneously reach for a glass of water in front of her. But preserved vision in blindsight does not afford anything like the form perception required to recognize a glass of water. It is easy to be misled here. One might naturally think that DB's capacity to discriminate between ' $\mathrm{X}$ 's and 'O's reveals residual form perception. However, in subsequent work Weiskrantz concluded 'against D.B.'s having a residual capacity for form discrimination' (1987: 77) on the basis that when the orientations of the components of figures were matched, DB's performance fell to chance. For instance, he could not discriminate an ' $\mathrm{X}$ ' from a ' $\triangle$ ', nor a triangle with straight sides from one with curved sides, nor squares from (non-extreme) rectangles. ${ }^{26} \mathrm{DB}$ was also

\footnotetext{
${ }^{26}$ Extreme rectangles have orientation components almost entirely along their lengths and so can be discriminated from non-extreme rectangles on this basis.
} 
quite unable to make same/different judgements when pairs of ' $\mathrm{X}$ 's and ' $\mathrm{O}$ 's were presented in his blindfield. This all suggests that DB cannot combine elements into shapes and so does not see visual form, let alone objects proper (Weiskrantz, 2009a: chpt. 11; Kentridge, 2015: §4; though see Footnote 28).

More striking is data from Alexander and Cowey (2010) which considers the basis of discrimination and detection performance in two blindsight patients (GY and MS). These patients were asked to locate stimuli in one of the four quadrants of their visual field (Figure 12). The stimuli were matched in luminance but differed as to whether they exhibited a sharp luminance edge. The Gaussian (Figure 12, bottom left) matched the peak or mean luminance of the square (top left), and the Gabor (bottom right) matched the contrast and mean luminance of the square wave (top right). MS's performance was high for square and square wave. However, it fell to chance for the Gabor and Gaussian. This suggests that MS's sensitivity consisted exclusively in a capacity to detect sharp luminance contours, i.e., sudden changes in luminance. The loss of such information also impaired GY but he remained above chance on all stimuli. However, in a subsequent experiment, GY was asked whether a stimulus was presented in a yes or guess paradigm. In this experiment, when stimuli had sharp edges and/or sudden on- or offsets, he performed well. But when the stimulus was a Gaussian with a slow onset or no offset, he fell to chance with red and green stimuli. Performance was preserved for blue stimuli, but no test was done with a Gaussian with a slow onset and no offset. Consequently, no evidence was found of capacities not potentially exclusively based on either sharp luminance contours or stimulus transients.

These findings are consistent with previous work on patient CS showing abolition of performance and awareness when ramping on- and offsets were used with Gaussians as opposed 
to square waves (Sahraie et al., 2002: esp. 253 and Figure 3D) as well as with previous results for GY (Weiskrantz et al., 1991; Barbur et al., 1994; Weiskrantz et al., 1998) showing the importance of temporal on- and offsets in mediating performance. The idea that blindsight involves loss of form and object perception is also consistent with Azzopardi and Hock's (2011; see also Azzopardi, 2001b) demonstration that motion detection in GY is limited to detection of 'objectless' first-order motion energy (i.e. spatiotemporal changes in luminance; Adelson \& Bergen, 1985) as opposed to detection of changes in position or shape (Sperling \& Lu, 1998).

Subsequent experiments from Alexander and Cowey (2010) investigated the nature of GY's apparent residual sensitivity to color (see also Alexander \& Cowey, 2013). In one experiment, GY was able to identify a Gaussian patch as red or green with near perfect accuracy. But again, it would be hasty to conclude that GY can see colors. For when the patch was slowly uncovered (or appeared on the screen whilst GY had his eyes closed), performance was completely obliterated. Similarly, whilst GY scored 92\% when asked to discriminate red and blue stimuli, his performance fell to $48 \%$ when he closed his eyes and opened them after the onset of the stimuli (likewise when discriminating between a red and a blank).

Based on their findings, Alexander and Cowey conclude that blindsight is restricted to the ability to detect "'events" varying in 'subjective salience' (532), an idea which traces back to Humphrey's (1974) proposal 'of stimulus salience in blindsight, whereby different stimuli might “catch the eye" to different extents' (Cowey, 2010: 6). It is a nice question how exactly to think about stimulus salience on this view. In particular, we might distinguish between conspicuity: the extent to which a given location stands out from its surrounds in respect of a given feature type (e.g., intensity, color, or motion); and salience proper: the extent to which a given location stands 
out from its surrounds full stop, i.e., in a 'feature-agnostic' manner (Veale et al., 2017: 2). ${ }^{27}$ On either understanding, no absolute value of any feature would be attributed to any location in blindfield vision. Instead, subjects would experience one or more regions simply as different from their surrounds in relation to a specific feature category, or just as different. ${ }^{28}$

Note that the salience hypothesis is quite consistent with the preservation of mechanisms which process color and other featural information. In the case of color, it appears that even rudimentary color constancies are lost in blindsight (Kentridge et al., 2007-with DB). However, sensitivity to wavelength independent of luminance is spared (Stoerig \& Cowey, 1992; Kentridge et al., 2007). In line with this, Alexander and Cowey (2010) found that GY could not discriminate a blue stimulus from a yellow stimulus if the latter were at much higher luminance, suggesting that wavelength contributes to salience independent of luminance, with blue

${ }^{27}$ For a formal model of conspicuity and salience see Itti et al. (1998). They propose that low-level visual features are initially represented on 42 feature maps: 6 for intensity, 12 for color and 24 for orientation. (To which, as they note, motion needs adding.) These maps are then combined by a process of normalization, rescaling and addition into three 'conspicuity' maps. (Again, to which motion conspicuity needs adding.) Finally, these maps are normalized and summed into a 'salience' map. For a detailed consideration of how salience is computed neurally see Veale et al., 2017 who propose a crucial rule for the superior colliculus in salience computation. Thanks to Masatoshi Yoshida for drawing my attention to this model.

${ }^{28}$ Conspicuity and/or salience cannot easily explain all residual performance in Weiskrantz's original patient, DB. However, there is reason to think that DB is not, or is no longer, a pure case of blindsight. As previously noted, the metal clips in his brain prevent accurate assessment of his lesion. Moreover, more recent reports suggest he experiences after-images (Weiskrantz et al., 2003) and appears to have recovered some genuine sight (Trevethan et al., 2007; Weiskrantz, 2009a). Commenting on these findings, Cowey writes: 'How ironic if the discovery of blindsight proves to be based on a patient who does not possess it!' (2010: 7) 
wavelengths being especially salient. Thus, whilst blindsight involves the loss of color vision per se, this does not mean the loss of all chromatic information processing.

Morland et al. (1999) found that GY was able to make veridical matches of colored (and moving) stimuli within and across his blind and sighted hemifields. ${ }^{29}$ Strikingly, however, they found that he could not make such matches for luminance even though he could match stimuli for luminance within his blindfield. Morland et al. conclude that GY's luminance-based percept in his blindfield 'is in no way comparable to the percept of brightness' (1194), i.e. luminance as perceived in his sighted field. In other words, GY does not seem to experience brightness but instead seems to enjoy a qualitatively different percept of luminance from that found in neurotypical vision.

To summarize, the behavioral evidence makes clear that blindsight is not simply weak sight but sight whose familiar contents have been dramatically stripped away or changed beyond comparison (cf. Tapp, 1997: 70). Subjects apparently do not see colors or shapes, still less objects. And the subjective signature of their sensitivity to wavelength or luminance is very different to neurotypical vision, arguably showing up only in the extent to which a given region 'stands out' temporally or spatially, and in the case of luminance being incommensurable with the familiar percept of brightness.

\footnotetext{
${ }^{29}$ Morland et al. take the view that successful matching is indicative of conscious awareness of the matched stimuli. Whilst I concur, we should be cautious in concluding from cross-hemifield matches that awareness is of the same features in both hemifields. In particular, the data from Alexander and Cowey throw grave doubt on the suggestion that GY is conscious of color per se.
} 
Minded of these points, consider the following reports from blindsight subjects concerning their subjective experience.

(i) Lack of color. GY stresses 'an absence of color sensation' (Stoerig \& Barth, 2001: 582).

(ii) Lack of bound features. 'I'm aware of individual functions of sight. Sometimes I'm aware of a motion, but that motion has no shape, no color, no depth, no form, no contrast. Sometimes I can tell you what orientation it's at but then we lose everything else'. (PBS interview, see Footnote 3.)

(iii) Looks like nothing. Another early patient of Weiskrantz's, EY, when asked to describe a light he was able to reach for, said: 'But it does not actually look like a light. It looks like nothing at all.' 'I had an impression that something was there. Where it was made a greater impression than what it was.' (Weiskrantz, 1980: 378)

(iv) Feelings. GY often reports that he has a "feeling" of something happening in his blind field and, given the right conditions, that he is absolutely sure of the occurrence' (Zeki \& ffytche, 1998: 30). Similarly, DB (on whom see Footnote 28) in discriminating on the basis of orientation reports 'a "feeling" that the stimulus was either pointing this or that way, or was “smooth" (the O) or "jagged” (the X)' (Weiskrantz et al., 1974: 721). Likewise, in a red/green discrimination task, Weiskrantz notes that 'he reported "green" when he had a "stronger feeling of something being there," and said "red" when he "felt there was nothing there."' (ibid: 720). Interestingly, GY appears to exhibit the opposite pattern explaining his capacity to discriminate red from green by saying that the red 'produced a stronger feeling whereas the green did not' (Alexander \& Cowey, 2010: 524). See further discussion below on these reported feelings. 
(v) Transients and shadows. With moving stimuli, GY says that 'his experience resembles that of a normal person when, with the eyes shut, he looks out of the window and moves his hand in front of his eyes.... like a "shadow", and more specifically "“a black shadow moving on a black background"' (Zeki \& ffytche, 1998: 29; see also Beckers \& Zeki, 1995; Weiskrantz, 1997: 145). In a similar vein, GY tells Stoerig and Barth: 'He is aware of "something moving" but it appears as "black on black," like "a mouse under a blanket"” (2001: 582). Finally, Barbur et al. relate that GY reports a flashed target as "“a dark shadow", located in the "blind" hemifield' and a higher illumination target 'sometimes appears as a localized, bright flash' (1980: 910).

(vi) Seeing and imagining. I have already noted GY's claim that he was 'seeing a lot' in Kentridge et al., 1997. A more curious report is found in King et al., 1996. In their study, GY was asked to discriminate between a stationary and an oscillating grating. He performed excellently and confidently. 'When asked to explain why he was so confident in his performance, GY commented that "I imagined flicker, but I didn't actually see flicker."' (King et al., 1996: 9, emphasis in original)

(vii) Negative unawareness. When using low contrast stimuli GY 'spontaneously remarked that the awareness score here should be "minus one or minus two", implying that there might be, for him, degrees of unawareness' (Zeki \& ffytche, 1998: 30).

Many of these reports are consistent with the behavioural evidence. Lack of color sensations is consistent with the idea that wavelength information is revealed only in the form of subjective salience. Likewise, GY's report that he is only 'aware of individual functions of sight' is consistent with a loss of form and object perception. It is also tempting to relate other reports 
to the conspicuity/salience hypothesis advanced above. For what would it be like to experience a region as different yet fail to attribute any absolute value to it or its surround? Might it not be natural to say that it feels as if there were something different about that region even if one cannot say what it is. Or that a given stimulus presents a stronger impression than another, though neither is presented as having any absolute value in respect of (say) luminance. ${ }^{30}$

Other aspects of blindsight subjects' reports are telling in different ways. First, it does not make sense to speak of degrees of unawareness. Unawareness is simply unawareness. Thus, the fact that GY spontaneously distinguishes between levels of unawareness, strongly suggests that some of what he describes as unawareness is really very dim awareness. As with Mazzi et al.'s patient SL who counted very weak awareness as unawareness when offered only a dichotomous measure, this is consistent with the central tenet of QDC that blindsight involves severely and qualitatively degraded awareness unreported due to conservative response biases.

Second, not only do the reports make common use of visual language (Foley, 2015), e.g., GY talks of dark shadows, flashes, flicker etc., but many of GY's descriptions bear a striking similarity to those of neurotypical subjects when vision is degraded. Blindsight subjects' reports are often negative, stressing the absence of normal visual qualities, as in EY's remark that the light 'looks like nothing at all'. Similarly, neurotypical subjects may report masked or threshold stimuli as 'more like nothing' than a stimulus (Stoerig et al., 2002: 572). These reports suggest

\footnotetext{
${ }^{30}$ For further discussion of the phenomenology of blindsight see Stoerig \& Barth, 2001: 582; Overgaard, 2011; Kentridge, 2015; Mazzi et al., 2019. For persuasive reasons to consider type II blindsight to be genuinely visual despite its degradation, see Foley, 2015; Macpherson, 2015. Note that from the point of view of QDC, the type I/type II distinction is merely a matter of whether visual awareness is acknowledged, so these arguments apply tout court.
} 
that there is a way that things look, but that it is more notable for what is absent than what is present.

More interestingly, consider GY's claim that he did not see but imagined flicker. Such a claim is naturally understood as grounded in the characteristic difference in 'force' and 'vivacity' — as Hume (1978: 1.1.1) notoriously put it — between 'violent' and 'lively' seeing and 'faint' and 'feeble' imagining. Again, similar descriptions are offered by neurotypical subjects when asked to describe the appearance of masked stimuli. Thus, Price (drawing on his, 1991: 192) reports:

When stimuli such as words are backward pattern masked, [neurotypical] subjects may report the percept of a word that has visual qualities but seems more like a mental image than a word on the display screen .... For example, the following descriptions were recorded from subjects during the forced-choice categorization of animate and inanimate words described earlier: The experience was "not a visual representation of what it looks like when you see a word in the machine' or was 'like an after-image'. (Price, 2001: 356)

A similar point can be illustrated by considering GY's descriptions of moving stimuli. Not only do subjective reports conform well with the behavioural data, specifically motion detection being limited to detection of 'objectless' first-order motion energy. But, once more, we find clear echoes of GY's attempts to describe his percepts from neurotypical subjects if we turn to the literature on 'pure' or $\varphi$-apparent motion. $\Phi$-motion is experienced when two stimuli (e.g., 
disks) are successively presented close by each other with an inter-stimulus interval in the range 30-50ms. The two stimuli appear stationary. However, as von Fieandt describes it, there is also 'a peculiar phenomenal motion ... an objectless movement, or "pure motion" as Wertheimer described it. Without seeing any moving objects of figures, there [is] a clear impression of motion from one place to another' (1966: 263, quoted in Steinman et al., 2000: 2259, fn.3). In their extensive study of the phenomenon, Steinman et al. write:

When generated by bright stimuli on a dark background, $\varphi$ appears as a moving dark black, or, some say, a dark purple, flag-like region, that flaps back and forth between, and slightly around, the stationary pair of slightly flickering disks producing it. Its shape is ambiguous. It does not look like an object, so observers, as one might expect, describe its appearance with difficulty, but consensus about the percept of something dark moving ... is readily achieved. (2000: 2260$)$

The comparison with GY's descriptions of moving stimuli as dark or black shadows against a black background is striking. Of course, in neurotypical perceivers this motion is perceived alongside percepts of stationary objects. Since, GY cannot perceive objects in his blindfield, we might speculate that GY's experience of moving stimuli therein is strictly limited to such pure motion percepts.

Finally, and relatedly, consider Stoerig and Barth's (2001) finding that GY was able to make a phenomenal match across his blind and sighted fields between a moving contrast-defined bar (Figure 13(b)) and a moving texture of low contrast (Figure 13(a)). This match went hand-in- 
hand with discriminative sensitivity: GY performed very similarly in discriminating the orientation and direction of motion in respect of these matched stimuli (see also Morland et al., 1999). This combination of phenomenal and behavioral match strongly suggests that performance across both fields is subserved by a single conscious visual signal as QDC proposes. Interestingly, the phenomenal match was improved by shifting to an apparent motion stimulus (i.e., one in which the stimulus was removed from the middle frames). As Stoerig and Barth note, this may imply 'that instead of motion per se, only the on- and offsets of a moving object [are] sensed, which would suffice to discriminate motion direction' (582; again see Alexander \& Cowey, 2001b, 2010).

Drawing these threads together, the following conclusions appear warranted. First, vision in blindsight is severely impaired. Second, such vision is qualitatively quite different from neurotypical sight. Objects, shapes, and colors are missing. And residual sensitivity appears to show up solely in terms of conspicuity and/or salience, and in the case of luminance in a manner quite different from brightness. Third, vision in blindsight is at least sometimes conscious. Zeki and ffytche are surely right to be left 'with little doubt that [GY is] able to experience consciously stimuli' (1998: 30; Morland et al., 1999; Barbur et al., 1993). Fourth, behavioral data and reported experience are in close alignment. Reported phenomenology corresponds clearly to residual behavioral capacities, and there is no evidence of a class of visually discriminable stimuli with respect to which phenomenology is never reported (which is absolutely not to say that performance is always accompanied by acknowledged awareness - plainly it is not). Finally, certain subjective reports bear a clear resemblance to reports made by neurotypical subjects in cases of vision degraded by masking and, most strikingly, in relation to pure motion percepts. Moreover, GY is willing and able to make phenomenal matches across his intact and damaged 
fields in respect of carefully designed apparent motion stimuli. This is all precisely as QDC would predict.

Throughout this section I have relied on reports from blindsighted subjects, most especially GY. This might seem problematic given that QDC denies that blindsight subjects' subjective reports of absence of awareness should be taken at face value. However, I am not selectively endorsing some reports and ignoring others. Rather all reports are treated equally as data to be evaluated alongside further, e.g., behavioral data, and within the context of a more general model. The argument made is that QDC is the best model which accounts for and predicts the full range of first-person and behavioural evidence. The positive phenomenological reports of this section are highlighted here because they represent discriminating evidence in favor of QDC.

\section{Explaining conservativeness and instability}

If blindsight really is degraded conscious vision, how can we account for those features which have led to its misinterpretation as involving unconscious vision, that is, the conservative and, with static stimuli, unstable criteria which it is naturally attended by? This issue is especially pressing for QDC since, by hypothesis, no explanation in terms of lack of conscious awareness is available. Let us begin then with conservativeness. If blindsight is conscious, why do subjects routinely deny it?

The first point to note is that the kinds of conservative biases found in blindsight are less exceptional than commonly presumed. Neurotypical subjects exhibit 'systematic and robust' conservative biases especially when operating near the threshold of vision (Björkman et al., 1993: 81; Sand, 2016). Consider Figure 14 which shows the relation between individual 
detection criteria and sensitivities in a masking paradigm. (For a similar pattern with very lowcontrast stimuli, see Railo et al., 2020: Figure 1C.) As can be seen, subjects are highly variable in their criterion placement but in general adopt significantly conservative criteria. Moreover, there is a clear inverse correlation between their sensitivity and conservativeness. This is naturally explained if subjects cleave to a criterion which keeps their false alarm rate low (i.e., the socalled Neyman-Pearson objective; Treisman \& Watts, 1966).

Azzopardi and Cowey found that GY adopted a criterion of 1.867 in their yn task. They comment that this would be sufficient to explain observed dissociations between yn and 2ifc responding as measured with percent correct so long as $d^{\prime}$ was about 1 (1998: 298). Comparison with data from neurotypical subjects suggests that this pairing of sensitivity and criterion, whilst extreme, is not truly exceptional (see the red dot representing GY in Figure 14). ${ }^{31}$ As a result, the explanatory challenge posed by conservative bias in blindsight may be met by relatively modest supplementary materials. ${ }^{32}$

\footnotetext{
${ }^{31}$ Might GY have felt expected to say 'yes' sometimes even though he never saw anything? Whilst felt expectations are undoubtedly a valid concern in general (see further below), they are significantly mitigated in the present instance since Azzopardi and Cowey deliberately randomly intermixed blocks of a 'yes or guess' (yg) task in order 'to minimize guessing in the yn task' (1998: 297). The fact that GY's yg performance exhibited negligible response bias suggests that GY did not feel an expectation to respond positively in the yn task. Indeed, if anything, the concern would be that his conservative criterion reflected the contrary expectation that he respond negatively in the yn condition.

${ }^{32}$ It is also unclear how representative GY is of blindsighted subjects in general since patients are rare and there are few epidemiological studies (though see Morland et al., 2004; Garric et al., 2019—on which see Phillips, 2020). For instance, ffytche and Zeki (2011) report on awareness in three patients with lesions to V1 (GN, FB and CG). None of the three subjects showed any evidence of type I blindsight. Whilst CG may be argued to have undetected islands
} 
The obvious place to look for such supplementary materials is to GY's criterion contents. In the last section, we saw that GY's blindfield lacks all the usual vestments of neurotypical vision: it is objectless, shapeless and colorless, and may be limited to mere conspicuity or 'feature-agnostic' salience. Given this, it is easily understandable that GY adopts a conservative criterion in a task where he is asked if he sees anything. As Stoerig and Barth suggest: 'his residual capacity is too much altered quantitatively and/or qualitatively for him to want to call it "vision."' (2001: 576; Foley, 2015; Morland et al., 1999) Moreover, on a natural understanding of 'things' as objects, he is simply right to deny seeing things. GY also denies awareness of any kind in some conditions. Again, this may be explained by the difference in character and content between his sighted and blind fields. As we have seen, subjects in binary tasks may classify weak experience together with no experience as unaware, reserving positive aware responses only for clear and almost clear experience.

The puzzle of unacknowledged awareness likely has other complementary explanations. For instance, it is possible that in some tasks GY is simply aware that something has happened somewhere. Since his awareness is dominated by his sighted field, such vague awareness might

of spared cortex, GN and FB seem to have significant if 'crude' conscious vision despite complete loss of corresponding regions of $\mathrm{V} 1$. Both almost always report confident seeing and are able to draw and describe their experiences. Indeed, GN reports that 'there was little distinction between the visual experience in his intact and blind hemifields' when shown a Gaussian disc (ibid: 252). Moreover, crude estimates of sensitivity and criterion based on their data suggest only modestly conservative criteria $\left(c \approx 0.3\right.$ and 0.4 respectively, and $d^{\prime} \approx 1.8$ and 1.2 respectively). As Binsted et al. write, it may be that GY's deficit 'is profound ... and does not occur universally after damage to V1' (2007: 12669). It may also be that his conservative bias is especially pronounced. 
naturally be attributed to his sighted field and so awareness in the blindfield reported as entirely absent (compare discussion of anti-pointing in MS in Smits et al., 2019).

An additional piece to the story concerns motivation. In everyday life, blindsighted subjects regard themselves as completely blind in their scotoma. And in many stimulus conditions, they do indeed lack any residual capacity. Consequently, they may regard the psychophysical tasks they are engaged in not just as tedious, but pointless: frustrating and fruitless guessing exercises. In such circumstances, they may express their frustration by insisting that they don't see anything, that for them there is nothing there. Equally, perhaps they sometimes simply 'give up' defaulting to habitually denying awareness rather than earnestly attending to scraps of consciousness on every trial which they doubt are of any use to them in performing the task anyway (cf. Azzopardi \& Cowey, 1998). Either way, the psychophysical upshot will be a highly conservative criterion.

In the case of GY, issues of motivation may be still more complex. GY has selfconceived as blind in his right hemifield since an eight-year-old boy (Barbur et al., 1980: 906). From early adulthood he has been a participant in a very large number of 'long and arduous' (ibid: 925) psychophysical studies. ${ }^{33} \mathrm{GY}$ is invested in these studies. He is flown to labs around the world. He reads his own literature. He appears in documentaries. His sizeable scientific contribution to this work is significantly predicated on his condition being revolutionary in involving performance outside awareness. In addition, the scientific theories of the experimentalists GY has come to know through this work are also significantly based on this

\footnotetext{
${ }^{33}$ GY was born in 1956 (Stoerig \& Barth, 2001: 576). He is twenty-two in the studies reported in Barbur et al., 1980.
} 
interpretation: they too are invested. Lastly, like all study participants, GY will be sensitive to the expectations of his experimenters (Kentridge, 2015). For all these reasons, it would be natural for GY to be motivated to avoid saying that he sees at all —as opposed to describing his experience using the more mundane picture offered by QDC. The history of psychology suggests that such factors are underestimated at our peril.

We can now see then that the materials for an explanation of criterion conservativeness are plentiful — even if, of course, the precise details and contributions of different factors await future investigation.

What, finally, can be said about the distinctive instability in GY's criterion in relation to static stimuli? Here my discussion is inevitably more speculative, largely because criterion placement and stabilization in general is not a well-understood phenomenon. ${ }^{34}$ However, building on a suggestion by Azzopardi and Cowey (2001a), I here offer an approach to criterion instability in blindsight grounded in the fact that residual vision in blindsight is so degraded that it is largely non-functional in everyday life where instead subjects rely entirely on their unaffected fields.

In their discussion of criterion instability, Azzopardi and Cowey (2001a) look to criterion setting theory (CST) (Treisman \& Williams, 1984) for a general approach to criterion setting in sensory discrimination tasks. According CST, in addition to global decisional factors (e.g., desiring to avoid false alarms), an optimal criterion is maintained in a given task by two mechanisms: a stabilization mechanism and a probability tracking mechanism. The stabilization mechanism continually updates one's criterion so that it stays close to the mean of the signal

\footnotetext{
${ }^{34}$ Nor in fact is the relation between 2 ifc and yn responding well-understood as discussed above in Footnote 14.
} 
distribution and away from extreme values. It does this based on 'stabilization indicator traces'weighted, decaying records of how far a given trial's sensory response differed from that trial's criterion (Lages \& Treisman, 2010: §2.1). In contrast, the probability tracking mechanism updates the criterion to exploit anticipated continuity in the environment based on 'responsedependent tracking indicator traces', decaying positive or negative traces corresponding to previous responses. For example, in a detection task a positive 'yes' response will lay down a negative trace, lowering the criterion on subsequent trials. By integrating and appropriately weighting the traces from these two mechanisms, an optimal, stable criterion can be achieved over time.

Azzopardi and Cowey suggest that criterion instability in blindsight arises because of both 'poor tracking' and 'noisy or overcompensating stabilization' (2001a: 14). ${ }^{35}$ They speculate that the former may reflect the fact that GY lacks implicit knowledge of the variability of his environment due to his lack of 'experience of the continuity of visual inputs' (16). And they propose that the latter may be due to noise in the inputs to, or storage of, indicator traces.

Here, I propose a further, potentially complementary way of thinking about problems with criterion stabilization in blindsight. ${ }^{36}$ Of crucial relevance to the stabilization of a criterion

\footnotetext{
${ }^{35}$ Specifically, Azzopardi and Cowey report evidence of sequential dependencies in GY's responses in relation to certain stimuli (that is effects of trial $n$ responses on trial $n+1$ responses). The dependencies they find are precisely what one would predict if stabilization and tracking mechanisms were imbalanced.

${ }^{36}$ Two other important treatments of response patterns in blindsight are Ko \& Lau, 2012, and Miyoshi \& Lau, 2020. Both offer detection theoretic approaches to blindsight consistent with QDC and accounts of criterion setting which are potentially complementary to my own proposals. Ko and Lau first suggest that a conservative criterion in blindsight can be explained by a failure to update one's pre-lesion criterion. Note, however, that this explanation
} 
is the size of the available trace sample for updating. If few traces are available, the criterion will be highly variable as each new stimulus will have a large impact on trace summation. As more traces are available, the criterion will become increasingly stable (Lages \& Treisman, 2010: 412). One relevant factor here is the respective decay rates of the traces. The faster their decay, the smaller the sample. However, the size of the sample is also crucially dependent on a process which Lages and Treisman call projection. Projection is the addition of accumulated traces from relevant stimuli from the more distant past into the trace pool. This capacity 'to accumulate a

makes the questionable assumption that the difference between increasing noise and decreasing signal is meaningful. It will not be if the detection theoretic decision axis represents a parameter such as ratio of hits to misses or expected value (again see Lages \& Treisman, 1998 on the difference between signal detection theory and sensory memory theory). Ko and Lau then develop Azzopardi and Cowey's criterion jitter account of dissociations between estimated 2ifc and yn sensitivity by building a simple computational model. This shows that a simple learning rule will fail to converge on optimality (i.e., generate jitter) following a dramatic (though not gradual) loss of sensitivity. In turn, this provides a valuable "'proof of concept' ... that the psychophysical properties of blindsight can be explained in terms of criterion learning" (1409). However, further work is needed to justify the model's postulated learning rule, to explore complementary learning mechanisms, and to address the concern that the simulated data are substantially the product of a workaround for instances where the model's criterion parameter becomes infinite or undefined. Miyoshi and Lau's rather different approach makes the interesting suggestion that the dissociation between estimates of $d^{\prime}$ in 2ifc and yn tasks in blindsight can be explained in terms of additional Gaussian noise which is positively correlated across both intervals in 2ifc tasks. It is certainly a theoretical possibility that this could lead to the observed dissociation (see also: Yeshurun et al., 2008: 1847; Wickelgren, 1968: 116). However, in contrast to Wixted et al.'s (2018) example of participants in a police line-up who are correlated by design, it is unclear what motivates the postulation of correlated noise across intervals in blindsight. Finally, note that both approaches are distinctively motivated by their ability to explain impaired metacognition in blindsight. However, for the reasons set out in detail in the section on metacognition above, there is currently no secure empirical basis for the claim that this is a genuine explanandum. 
large residue of traces' enables the establishment of 'a well-stabilized permanent criterion' (ibid: 431). Put another way: effective detection and discrimination in criterion-based tasks draws critically on one's past experience. A subject familiar with relevant stimuli, will be able to draw on a reservoir of such traces to project into their trace pool. The naïve subject must do without, resulting in an unstable criterion.

Lages and Treisman apply this lesson to anisotropies in sensory discrimination, explaining the greater stability of our criterion for judging departures from verticality as compared to departures from novel angles, e.g., $13^{\circ}$, by appeal to the fact that we spend our lives monitoring whether or not objects are upright and so have much more experience discriminating such departures than with unusual angles. This in turn leads to a much larger reservoir of past traces, and thus a more permanent criterion, than with respect to idiosyncratic angles where we have much less experience, and so fewer traces to draw upon.

The same fundamental idea can be applied to blindsight. As Azzopardi and Cowey note, 'in his everyday life (outside the laboratory), GY is effectively blind is his scotoma' (2001a: 16). His 'blindsight [is] of little practical use in everyday life' (Alexander \& Cowey, 2010: 532). Indeed, anecdotally, some subjects with blindsight rely so completely on their sighted field they do not even realise that they enjoy any residual function beyond it prior to testing. Residual awareness of moving stimuli may be an exception to this rule but in the case of static stimuli, this strongly suggests that, in laboratory testing, blindsighted subjects will be unable to draw on any reservoir of traces from prior experience to project into their current trace pool and thereby help stabilize their current criterion. They lack a history of exploiting stimulation in their blindsight since such stimulation is not functional for them. As a result, they lack projectable traces of previously discriminated stimuli for use in stabilising their criterion. 
The fact that vision in blindsight is so severely degraded and consequently unused in ordinary life, may thus not only help to explain the conservative nature of responding (in conjunction with the various other factors identified above) but also suffice to explain criterion instability. ${ }^{37}$ Given this, QDC offers the promise of an elegant explanation of psychophysical performance in blindsight which relies on quite general models of sensory discrimination and criterion setting. No ad hoc auxiliary hypotheses are needed. For all these reasons, QDC should be our preferred approach to blindsight.

\section{Implications}

The near universal consensus about blindsight is that it involves preserved capacities for voluntary visual discrimination operating outside conscious awareness. This orthodoxy has repeatedly been invoked to make large claims about the cognitive and neural basis of consciousness, as well as its significance and proper measurement.

Neural correlates. In their landmark article initiating the contemporary search for the neural correlates of consciousness, Crick and Koch declare it 'an urgent matter to decide experimentally ... exactly which neural pathways are used in blindsight, since this information may suggest which neural pathways are used for consciousness and which not' (1990: 266). In line with this, numerous theorists have appealed to blindsight to evidence particular proposals

\footnotetext{
${ }^{37}$ If this explanation is correct, we can make two tentative predictions. First, that it may be possible to induce criterion instability in neurotypical subjects by providing extensive random feedback. This said, the parallel here with random number generation (Treisman \& Faulkner, 1987; suggested to me by Tarryn Baldson) indicates that some thirty-five hours of such feedback might be needed to produce an effect (Neuringer, 1986). Second, that in cases of degraded vision due, for instance, to masking we should find criterion instability if the resultant vision is severely and qualitatively degraded, and of a kind which has hitherto been non-functional for the subject.
} 
concerning neural correlates. For instance, Lamme cites blindsight as offering 'substantial evidence in favor of the theory that ... visual awareness is critically dependent on feedback connections to the primary visual cortex' (2001: 209; see also Pascual-Leone \& Walsh, 2001; Tong, 2003; Silvanto et al., 2005; Brogaard, 2011). Many others, including Crick and Koch (1998: 103) themselves, argue that blindsight provides evidence for the involvement of prefrontal areas in awareness (LeDoux et al., 2020).

Cognitive requirements. Many theorists take blindsight to demonstrate that 'an entire stream of processing may unfold outside of consciousness' (Dehaene \& Naccache, 2001: 5; Brown et al., 2019: 765). Consequently, they argue that a core lesson of blindsight is that consciousness requires some form of higher cognitive processing (LeDoux et al., 2020; Dehaene et al., 2017), either in the form of global broadcasting of information (Dehaene \& Naccache, 2001; Dehaene, 2009, 2014; Silvanto, 2015), or in the form of capacities for reflexive, higherorder monitoring (e.g., Weiskrantz, 1997; Lau \& Rosenthal, 2011; Rosenthal, 2019).

Function of consciousness. Blindsight has also been held to raise profound questions about the function or value of conscious awareness. After all, if patient TN (de Gelder et al., 2008) can navigate a corridor strewn with objects without consciousness, it is natural to wonder what need there is for consciousness in navigating our environments more generally? Moved by this thought, some have even been led to wonder whether consciousness has any useful function, or whether it is instead best thought of as an evolutionary spandrel (e.g., Blakemore, 2005). Correspondingly, there is now a large philosophical literature which draws on blindsight to explore the functional, epistemic and conceptual implications of the absence of awareness (e.g., Campbell, 2004; Dretske, 2006; Smithies, 2016). 
Measurement of consciousness. In an influential and wide-ranging review of measures of consciousness, Seth et al. consider a traditional approach to measuring consciousness which they label Worldly Discrimination Theory. According to this theory, 'a person shows they are consciously aware of a feature in the world when they can discriminate it with choice behaviour' (2008: 314; Dienes \& Seth, 2010). Seth et al. quickly reject this theory on the grounds that it implies — in their eyes, obviously falsely — that 'blindsight patients see consciously' (315). Far more generally, blindsight is used to test the adequacy of different behavioral and neural measures of consciousness. According to this logic, if a measure deems blindsight conscious, it cannot be adequate (cf. Maniscalco and Lau, 2012 on type 2 measures of awareness discussed above).

The burden of our discussion has been to argue that performance in blindsight is not unconscious but rather reflects severely and qualitatively degraded conscious vision. If this is right, blindsight cannot be used to make any of the inferences just mentioned, neither about the neural correlates of consciousness, nor its cognitive basis, nor its function, nor its proper measurement. Given its central role within the scientific study of consciousness (Peters et al., 2016, LeDoux et al., 2020), many discussions and conclusions will need to be revisited. The revolution Weiskrantz hails will, in effect, need to be undone.

More positively, our discussion highlights crucial areas for future investigation. Most obviously, there is much more to uncover regarding the nature of residual awareness in blindsight and its relation to the patterns of conservative and unstable responding characteristic of the condition. Perhaps most importantly of all, our discussion advertises that a simple conscious-perception-only model of perceptual task performance is far more powerful than most theorists would today allow (Snodgrass, 2002). 
This result should be considered alongside related work on other neurological conditions which also appear to involve spared residual function in the absence of awareness. For instance, based on an apparent dissociations between explicit (e.g., 'old/new') and implicit (e.g., repetition priming) recognition in amnesia, theorists have postulated separable explicit and implicit longterm memory systems (e.g., Tulving \& Schacter, 1990; Squire, 2009). Similarly, apparent dissociations between covert and overt face recognition in prosopagnosia have been interpreted variously as evidence of separable overt and covert face recognition systems (Bauer, 1984), or as evidence of the disconnection of the facial recognition system from conscious awareness (e.g., de Haan et al., 1987, 1992; Schachter et al., 1988). Likewise, apparent dissociations between overt and covert perception in unilateral neglect have led theorists to conclude that unconscious perception includes high-level, semantic contents (Marshall \& Halligan, 1988; Husain, 2008). Indeed, perceiving an 'epidemic' of such dissociations, Weiskrantz suggests that they 'will emerge ... for every cognitive neurological condition’ (1990: 275).

Such a pattern might seem to lend strong indirect support to orthodoxy about blindsight, as merely another instance of a familiar pattern. However, very much in the spirit of the present discussion, Berry et al. $(2012,2014)$ show that a parsimonious single-system model of long-term memory provides an excellent fit to data from both neurotypical and amnesic individuals. Similarly, Farah et al. (1993) show that lesions to a single system can account for the apparent dissociations found in prosopagnosia. And although Farah et al. (1993) do not endorse such a model, this result is again consistent with a conscious-perception-only model of prosopagnosia on which the condition involves severely degraded but nonetheless conscious information sufficient for good performance in 'covert' but not 'overt' recognition tasks. Likewise, the alleged dissociations of awareness and performance in cases of extinction and neglect may also 
reflect conservative responding in relation to degraded vision as opposed to genuinely

unconscious contents (e.g., Farah et al., 1991; Gorea \& Sagi, 2002; Phillips, 2016). ${ }^{38}$ Placed

alongside each other, these results suggest a quite different pattern, one which lends strong

indirect support to our present hypothesis that performance in blindsight is similarly subserved by a single conscious signal.

\section{References}

Adelson, E. H., \& Bergen, J. R. (1985). Spatiotemporal energy models for the perception of motion. Journal of the Optical Society of America A, 2(2), 284-299.

https://doi.org/10.1364/josaa.2.000284

Alexander, I., \& Cowey, A. (2010). Edges, color and awareness in blindsight. Consciousness \& Cognition, 19(2), 520-533. https://doi.org/10.1016/j.concog.2010.01.008

Alexander, I., \& Cowey, A. (2013). Isoluminant colored stimuli are undetectable in blindsight even when they move. Experimental Brain Research, 225, 147-152.

https://doi.org/10.1007/s00221-012-3355-6

\footnotetext{
${ }^{38}$ Consider also work on the so-called 'two visual systems hypothesis', significantly motivated by putative double dissociations observed between patients with visual form agnosia and those with optic ataxia (Milner \& Goodale, 2006, 2008). In its strongest form, this hypothesis proposes that motor programming is exclusively guided by nonconscious signals associated with dorsal stream processes. But even critics of this view take the neuropsychological data to reveal 'the surprising extent to which skillful visuomotor action is possible in the absence of conscious seeing' (Briscoe \& Schwenkler, 2015: 1460). The present treatment should embolden theorists to reconsider the stronger and simpler hypothesis that, as with performance in blindsight, all action control may be subserved by a single conscious signal (Schenk \& McIntosh, 2010; Schenk, 2012; Hesse, et al., 2011; Phillips, forthcoming).
} 
Azzopardi, P., \& Cowey, A. (1997). Is blindsight like normal, near-threshold vision?

Proceedings of the National Academy of Sciences USA, 94(25), 14190-14194.

Azzopardi, P., \& Cowey, A. (1998). Blindsight and visual awareness. Consciousness \& Cognition, 7(3), 292-311. https://doi.org/10.1006/ccog.1998.0358

Azzopardi, P., \& Cowey, A. (2001a). Why is blindsight blind? In: Out of Mind: Varieties of Unconscious Processes. B. De Gelder, E. H. F. De Haan, \& C. A. Heywood (eds). Oxford: Oxford University Press, pp. 3-19.

Azzopardi, P., \& Cowey, A. (2001b). Motion discrimination in cortically blind patients. Brain, 124(1), 30-46. https://doi.org/10.1093/brain/124.1.30

Azzopardi, P., \& Hock, H. S. (2011). Illusory motion perception in blindsight. Proceedings of the National Academy of Sciences USA, 108(2), 876-881.

https://doi.org/10.1073/pnas.1005974108

Bachmann, T., \& Francis, G. (2013). Visual Masking: Studying Perception, Attention and Consciousness. Oxford: Elsevier, Academic Press.

Baldson, T., \& Azzopardi, P. (2015). Absolute and relative blindsight. Consciousness \& Cognition, 32, 79-91. https://doi.org/10.1016/j.concog.2014.09.010

Barbur, J. L., Harlow, J. A., \& Weiskrantz, L. (1994). Spatial and temporal response properties of residual vision in a case of hemianopia. Philosophical Transactions of the Royal Society of London B: Biological Sciences, 343, 157-66. https://doi.org/10.1098/rstb.1994.0018

Barbur, J. L., Watson, J. D., Frackowiak, R. S., \& Zeki, S. (1993). Conscious visual perception without V1. Brain, 116(6), 1293-1302. https://doi.org/10.1093/brain/116.6.1293 
Barbur, J. L., Ruddock, K. H., \& Waterfield, V. A. (1980). Human visual responses in the absence of the geniculocalcarine projection. Brain, 103(4), 905-928.

https://doi.org/10.1093/brain/103.4.905

Baseler, H. A., Morland, A. B., \& Wandell, B. A. (1999). Topographic organization of human visual areas in the absence of input from primary cortex. Journal of Neuroscience, 19(7), 261927. https://dx.doi.org/10.1523/JNEUROSCI.19-07-02619.1999

Bauer, R. M. (1984). Autonomic recognition of names and faces in prosopagnosia: a neuropsychological application of the Guilty Knowledge Test. Neuropsychologia, 22(4), 457-69. https://doi.org/10.1016/0028-3932(84)90040-x

Bayne, T. (2013). Agency as a marker of consciousness. In: Decomposing the Will. T. Vierkant, J. Kiverstein, \& A. Clark (eds). Oxford: Oxford University Press, pp. 160-182.

Beckers, G., \& Zeki, S. (1995). The consequences of inactivating areas V1 and V5 on visual motion perception. Brain, 118(1), 49-60. https://doi.org/10.1093/brain/118.1.49

Berry, C. J., Shanks, D. R., Speekenbrink, M., \& Henson, R. N. A. (2012). Models of recognition, repetition priming, and fluency: exploring a new framework. Psychological Review, 119(1), 40 -79. https://doi.org/10.1037/a0025464

Berry, C. J., Kessels, R. P., Wester, A. J., \& Shanks, D. R. (2014). A single-system model predicts recognition memory and repetition priming in amnesia. Journal of Neuroscience, 34(33), 10963-74. https://doi.org/10.1523/JNEUROSCI.0764-14.2014 
Binsted, G., Brownell, K., Vorontsova, Z., Heath, M., \& Saucier, D. (2007). Visuomotor system uses target features unavailable to conscious awareness. Proceedings of the National Academy of Sciences USA, 104(31), 12669-12672. https://doi.org/10.1073/pnas.0702307104

Björkman, M., Juslin, P., \& Winman, A. (1993). Realism of confidence in sensory discrimination: the underconfidence phenomenon. Perception \& Psychophysics, 54(1), 75-81. https://doi.org/10.3758/bf03206939

Blakemore, C. (2005). In celebration of cerebration. Lancet, 366(9502), 2035-2057. https://doi.org/10.1016/s0140-6736(05)67816-6

Block, N. (2001). Paradox and cross purposes in recent work on consciousness. Cognition, 79(12), 197-219. https://doi.org/10.1016/S0010-0277(00)00129-3

Block, N. (2005). Two neural correlates of consciousness. Trends in Cognitive Sciences, 9(2), 46-52. https://doi.org/10.1016/j.tics.2004.12.006

Blythe, I. M., Bromley, J. M., Kennard, C., \& Ruddock, K. H. (1986). Visual discrimination of target displacement remains after damage to the striate cortex in humans. Nature, 320(6063), 619-21. https://doi.org/10.1038/320619a0

Boly, M., Massimini, M., Tsuchiya, N., Postle, B. R., Koch, C., \& Tononi, G. (2017). Are the neural correlates of consciousness in the front or in the back of the cerebral cortex? Clinical and neuroimaging evidence. The Journal of Neuroscience, 37(40), 9603-

9613. https://doi.org/10.1523/JNEUROSCI.3218-16.2017 
Breitmeyer, B. G., \& Ganz, L. (1976). Implications of sustained and transient channels for theories of visual pattern masking, saccadic suppression, and information processing. Psychological Review, 83(1), 1-36.

Breitmeyer, B. G., \& Öğmen, H. (2006). Visual Masking: Time Slices Through Conscious and Unconscious Vision. Oxford: Oxford University Press.

Bridge, H., Thomas, O., Jbabdi, S., \& Cowey, A. (2008). Changes in connectivity after visual cortical brain damage underlie altered visual function. Brain, 131(6), 1433-1444. https://doi.org/10.1093/brain/awn063

Briscoe, R., \& Schwenkler, J. (2015). Conscious vision in action. Cognitive Science, 39(7), 1435-1467. https://doi.org/10.1111/cogs.12226

Brown, R., Lau, H. C., \& LeDoux, J. E. (2019). Understanding the higher-order approach to consciousness. Trends in Cognitive Sciences, 23(9), 754-768.

https://doi.org/10.1016/j.tics.2019.06.009

Campbell, J. (2004). Reference as attention. Philosophical Studies, 120(1-3), 265-76. https://dx.doi.org/10.1023/B:PHIL.0000033757.14408.47

Campion, J., Latto, R., \& Smith, Y. M. (1983). Is blindsight an effect of scattered-light, spared cortex, and near-threshold vision? Behavorial and Brain Sciences, 6(3), 423-47. https://doi.org/10.1017/S0140525X00016861

Celeghin, A., Bagnis, A., Diano, M., Méndez, C. A., Costa, T., \& Tamietto, M. (2019). Functional neuroanatomy of blindsight revealed by activation likelihood estimation meta- 
analysis. Neuropsychologia, 128, 109-118.

https://doi.org/10.1016/j.neuropsychologia.2018.06.007

Celeghin, A., de Gelder, B., \& Tamietto, M. (2015). From affective blindsight to emotional consciousness. Consciousness \& Cognition, 36, 414-25.

https://doi.org/10.1016/j.concog.2015.05.007

Clifford, C. W. G., Arabzadeh, E., \& Harris, J. A. (2008). Getting technical about awareness.

Trends in Cognitive Sciences, 12(2), 54-58. https://doi.org/10.1016/j.tics.2007.11.009

Cowey, A. (2004). The 30th Sir Frederick Bartlett Lecture: Fact, artefact, and myth about blindsight. Quarterly Journal of Experimental Psychology A, 57(4), 577-609. https://doi.org/10.1080/02724980343000882

Cowey, A. (2010). The blindsight saga. Experimental Brain Research, 200(1), 3-23. https://doi.org/10.1007/s00221-009-1914-2

Cowey, A., \& Stoerig, P. (1995). Blindsight in monkeys. Nature, 373(6511), 247-249. https://doi.org/10.1038/373247a0

Cowey, A., Alexander, I., \& Stoerig, P. (2011). Transneuronal retrograde degeneration of retinal ganglion cells and optic tract in hemianopic monkeys and humans. Brain, 134(7), 2149-2157. https://doi.org/10.1093/brain/awr125

Crick, F., \& Koch, C. (1990). Towards a neurobiological theory of consciousness. Seminars in the Neurosciences, 2, 263-275.

Crick, F., \& Koch, C. (1998). Consciousness and neuroscience. Cerebral Cortex, 8(2), 97-107. https://doi.org/10.1093/cercor/8.2.97 
Danckert, J., \& Rossetti, Y. (2005). Blindsight in action: what can the different subtypes of blindsight tell us about the control of visually guided actions? Neuroscience and Biobehavioral Reviews, 29(7), 1035-1046. https://doi.org/10.1016/j.neubiorev.2005.02.001

de Gelder, B., Pourtois, G., van Raamsdonk, M., Vroomen, J., \& Weiskrantz, L. (2001). Unseen stimuli modulate conscious visual experience: evidence from inter-hemispheric summation. Neuroreport, 12(2), 385-91. https://doi.org/10.1097/00001756-200102120-00040 de Gelder, B., Tamietto, M., van Boxtel, G., Goebel, R., Sahraie, A., van den Stock, J., Stienen, B. M. C., Weiskrantz, L., \& Pegna, A. (2008). Intact navigation skills after bilateral loss of striate cortex. Current Biology, 18(24), R1128-9. https://doi.org/10.1016/j.cub.2008.11.002

de Gelder, B., Vroomen, J., Pourtois, G., \& Weiskrantz, L. (1999). Non-conscious recognition of affect in the absence of striate cortex. Neuroreport, 10(18), 3759-63.

https://doi.org/10.1097/00001756-199912160-00007

de Haan, E. H., Young, A. W., \& Newcombe, F. (1987). Face recognition without awareness. Cognitive Neuropsychology, 4(4), 385-415. https://doi.org/10.1080/02643298708252045

de Haan, E. H., Bauer, R. M., \& Greve, K. W. (1992). Behavioural and physiological evidence for covert face recognition in a prosopagnosic patient. Cortex, 28(1), 77-95.

https://doi.org/10.1016/s0010-9452(13)80167-0

Debner, J. A., \& Jacoby, L. L. (1994). Unconscious perception: Attention, awareness, and control. Journal of Experimental Psychology: Learning, Memory, and Cognition, 20(2), 304317. https://doi.org/10.1037//0278-7393.20.2.304 
Dehaene, S. (2009). Conscious and nonconscious processes: distinct forms of evidence accumulation? Séminaire Poincaré, 12, 89-114.

Dehaene, S., \& Naccache, L. (2001). Towards a cognitive neuroscience of consciousness: Basic evidence and a workspace framework. Cognition, 79(1-2), 1-37. https://doi.org/10.1016/S00100277(00)00123-2

Dehaene, S., Lau, H., \& Kouider, S. (2017). What is consciousness, and could machines have it? Science, 358(6362), 486-492. https://doi.org/10.1126/science.aan8871

Dehaene, S. (2014). Consciousness and the Brain. Penguin Books.

Dienes, Z., \& Seth, A. K. (2010). Conscious and the Unconscious. In: Encyclopedia of Behavioral Neuroscience, Volume 1. G. F. Koob, M. Le Moal, \& R. F. Thompson (eds). Oxford: Academic Press, pp. 322-327.

Draine, S. C., \& Greenwald, A. G. (1998). Replicable unconscious semantic priming. Journal of Experimental Psychology: General, 127(3), 286-303.

Dretske, F. (2006). Perception without awareness. In: Perceptual Experience. T. S. Gendler, \& J. Hawthorne (eds). Oxford: Oxford University Press, pp. 147-180.

Eriksen, C. W. (1960). Discrimination and learning without awareness: a methodological survey and evaluation. Psychological Review, 67(5), 279-300. https://doi.org/10.1037/h0041622

Eysenck, M. W., \& Keane, M. T. (2010). Cognitive Psychology: A Student's Handbook (6th ed.). Psychology Press. 
Farah, M. J., Monheit, M. A., \& Wallace, M. A. (1991). Unconscious perception of “extinguished” visual stimuli: Reassessing the evidence. Neuropsychologia, 29(10), 949-958. https://doi.org/10.1016/0028-3932(91)90059-H

Farah, M. J., O’Reilly, R. C., \& Vecera, S. P. (1993). Dissociated overt and covert recognition as an emergent property of a lesioned neural network. Psychological Review, 100(4), 571-88. https://doi.org/10.1037/0033-295x.100.4.571

Fisk, G. D., \& Haase, S. J. (2007). Exclusion failure does not demonstrate unconscious perception. The American Journal of Psychology, 120(2), 173-204. https://www.jstor.org/stable/20445394

Fisk, G. D., \& Haase, S. J. (2013). Highly correlated stimuli do not necessarily facilitate the measurement of unconscious perception: Exclusion failure is hard to find in forced-choice tasks. Consciousness \& Cognition, 22(4), 1393-1402. https://doi.org/10.1016/j.concog.2013.09.006

ffytche, D. H., \& Zeki, S. (2011). The primary visual cortex, and feedback to it, are not necessary for conscious vision. Brain, 134(1), 247-57. https://doi.org/10.1093/brain/awq305

Foley, R. (2015). The case for characterising type-2 blindsight as a genuinely visual phenomenon. Consciousness \& Cognition, 32, 56-67. https://doi.org/10.1016/j.concog.2014.09.005

Frith, C., Perry, R., \& Lumer, E. (1999). The neural correlates of conscious experience: an experimental framework. Trends in Cognitive Sciences, 3(3), 105-114. https://doi.org/10.1016/s1364-6613(99)01281-4

Garric, C. Sebaa, A., Caetta, F., Perez, C., Savatovsky, J., Sergent, C., \& Chokron, S. (2019). Dissociation between objective and subjective perceptual experiences in a population of 
hemianopic patients: A new form of blindsight? Cortex, 177, 299-310.

https://doi.org/10.1016/j.cortex.2019.05.006

Gazzaniga, M. S., Fendrich, R., \& Wessinger, C. M. (1994). Blindsight reconsidered. Current Directions in Psychological Science, 3(3), 93-96. https://doi.org/10.1111/1467-

\section{$\underline{8721 . e p 10770443}$}

Georgy, L., Celeghin, A., Marzi, C. A., Tamietto, M., \& Ptito, A. (2016). The superior colliculus is sensitive to gestalt-like stimulus configuration in hemispherectomy patients. Cortex, $81,151-$ 161. https://doi.org/10.1016/j.cortex.2016.04.018

Gorea, A., \& Sagi, D. (2002). Natural extinction: A criterion shift phenomenon. Visual Cognition, 9(8), 913-936. https://doi.org/10.1080/13506280143000638

Green, D., \& Swets, J. (1966). Signal detection theory and psychophysics. New York, NY: Wiley.

Heeks, F., \& Azzopardi, P. (2015). Thresholds for detection and awareness of masked facial stimuli. Consciousness \& Cognition, 32, 68-78. https://doi.org/10.1016/j.concog.2014.09.009

Hesse, C., Franz, V. H., \& Schenk, T. (2011). Letter posting and orientation matching: two equivalent tasks in action and perception? Seeing and Perceiving, 24(2), 151-172. https://doi.org/10.1163/187847511X570105

Holender, D. (1986). Semantic activation without conscious identification in dichotic listening, parafoveal vision, and visual masking: a survey and appraisal. Behavioral and Brain Sciences, 9(1), 1-23. https://doi.org/10.1017/S0140525X00021269 
Hume, D. (1978). A Treatise of Human Nature. Oxford: Oxford University Press. (Originally published 1739-40.)

Humphrey, N. K. (1974). Vision in a monkey without striate cortex: a case study. Perception, 3(3), 241-255. https://doi.org/10.1068/p030241

Husain, M. (2008). Hemineglect. Scholarpedia, 3(2), 3681.

http://dx.doi.org/10.4249/scholarpedia.3681

Irvine, E. (2012). Consciousness as a Scientific Concept: A Philosophy of Science Perspective. Dordrecht: Springer.

Itti, L., Koch, C., \& Niebur, E. (1998). A model of saliency-based visual attention for rapid scene analysis. IEEE Transactions on Pattern Analysis and Machine Intelligence, 20(11), 1254-1259. https://doi.org/10.1109/34.730558

James, W. (1890). The Principles of Psychology, Vol. I. New York: Henry Holt \& Co.

Jannati, A., \& Di Lollo, V. (2012). Relative blindsight arises from a criterion confound in metacontrast masking: Implications for theories of consciousness. Consciousness \& Cognition, $21,307-314$.

Kahneman, D. (1968). Method, findings, and theory in studies of visual masking. Psychological Bulletin, 70(6, Pt.1), 404-425. https://doi.org/10.1037/h0026731

Kentridge, R. W. (2015). What is it like to have type-2 blindsight? Drawing inferences from residual function in type-1 blindsight. Consciousness \& Cognition, 32, 41-44. https://doi.org/10.1016/j.concog.2014.08.005 
Kentridge, R. W., Heywood, C. A., \& Weiskrantz, L. (1997). Residual vision in multiple retinal locations within a scotoma: implications for blindsight. Journal of Cognitive Neuroscience, 9(2), 191-202. https://doi.org/10.1162/jocn.1997.9.2.191

Kentridge, R.W., Heywood, C. A., \& Weiskrantz, L. (2007). Color-contrast processing in human striate cortex. Proceedings of the National Academy of Sciences USA, 104(38), 15129-15131. https://doi.org/10.1073/pnas.0706603104

King, S. M., Azzopardi, P., Cowey, A., Oxbury, J., \& Oxbury, S. (1996). The role of light scatter in the residual visual sensitivity of patients with complete cerebral hemispherectomy. Visual Neuroscience, 13(1), 1-13. https://doi.org/10.1017/S0952523800007082

Kitcher, P. (1982). Abusing Science: The Case against Creationism. Cambridge, MA: MIT Press.

Knotts, J. D., \& Shams, L. (2016). Clarifying signal detection theoretic interpretations of the Müller-Lyer and sound-induced flash illusions. Journal of Vision, 16(18), 1-4. https://doi.org/10.1167/16.11.18

Ko, Y., \& Lau, H. C. (2012). A detection theoretic explanation of blindsight suggests a link between conscious perception and metacognition. Philosophical Transactions of the Royal Society of London B: Biological Sciences, 367(1594), 1401-1411. https://doi.org/10.1098/rstb.2011.0380

Koizumi, A., Maniscalco, B., \& Lau, H. C. (2015). Does perceptual confidence facilitate cognitive control? Attention Perception \& Psychophysics, 77, 1295-1306.

https://doi.org/10.3758/s13414-015-0843-3 
Konstantinidis, E., \& Shanks, D. R. (2014). Don't bet on it! Wagering as a measure of awareness in decision making under uncertainty. Journal of Experimental Psychology: General, 143(6), 2111-2134. https://doi.org/10.1037/a0037977

Koster, N., Mattler, U., \& Albrecht, T. (2020). Visual experience forms a multidimensional pattern that is not reducible to a single measure: Evidence from metacontrast masking. Journal of Vision, 20(3):2, 1-27. https://doi.org/10.1167/jov.20.3.2

Lages, M., \& Treisman, M. (1998). Spatial frequency discrimination: visual long-term memory or criterion setting? Vision Research, 38(4), 557-572. https://doi.org/10.1016/s0042$\underline{6989(97) 88333-2}$

Lages, M., \& Treisman, M. (2010). A criterion setting theory of discrimination learning that accounts for anisotropies and context effects. Seeing and Perceiving, 23(5-6), 401-34. https://doi.org/10.1163/187847510x541117

Lamme, V. A. F. (2001). Blindsight: the role of feedforward and feedback corticocortical connections. Acta Psychologica, 107(1-3), 209-228. https://doi.org/10.1016/s0001$\underline{6918(01) 00020-8}$

Lamme, V. A. F. (2006). Towards a true neural stance on consciousness. Trends in Cognitive Sciences, 10(11), 494-501. https://doi.org/10.1016/j.tics.2006.09.001

Lamme, V. A. F. (2010). How neuroscience will change our view on consciousness. Cognitive neuroscience, 1(3), 204-220. https://doi.org/10.1080/17588921003731586 
Lau, H. C., \& Rosenthal, D. (2011). Empirical support for higher-order theories of conscious awareness. Trends in Cognitive Sciences, 15(8), 365-73.

https://doi.org/10.1016/j.tics.2011.05.009

Lau, H. C. (2008). Are we studying consciousness yet? In: Frontiers of Consciousness: Chichele Lectures. L. Weiskrantz, \& M. Davies (eds). Oxford: Oxford University Press, pp. 245-58.

Lau, H. C., \& Passingham, R. E. (2007). Unconscious activation of the cognitive control system in the human prefrontal cortex. The Journal of Neuroscience, 27(21), 5805-5811. https://doi.org/10.1523/JNEUROSCI.4335-06.2007

LeDoux, J. E., Michel, M., \& Lau, H. C. (2020). A little history goes a long way toward understanding why we study consciousness the way we do today. PNAS, 117(13), 6976-6984. https://doi.org/10.1073/pnas.1921623117

Lloyd, D. A., Abrahamyan, A., \& Harris, J. A. (2013). Brain-stimulation induced blindsight: unconscious vision or response bias? PLOS ONE, 8(12), e82828. https://doi.org/10.1371/journal.pone.0082828

Macmillan, N. A. (1986). The psychophysics of subliminal perception. Behavioural and Brain Sciences, 9(1), 38-39. https://doi.org/10.1017/S0140525X00021427

Macmillan, N. A., \& Creelman, C. D. (2005). Detection theory: A user's guide (2nd ed.). Lawrence Erlbaum Associates Publishers.

Macpherson, F. (2015). The structure of experience, the nature of the visual, and type 2 blindsight. Consciousness \& Cognition, 32, 104-128.

https://doi.org/10.1016/j.concog.2014.10.011 
Maniscalco, B., \& Lau, H. (2010). Comparing signal detection models of perceptual decision confidence. Journal of Vision 10(7), 213. https://doi.org/10.1167/10.7.213

Maniscalco, B., \& Lau, H. (2012). A signal detection theoretic approach for estimating metacognitive sensitivity from confidence ratings. Consciousness \& Cognition, 21(1), 422-430. https://doi.org/10.1016/j.concog.2011.09.021

Maniscalco, B., Peters, M. A. K., \& Lau, H. (2016). Heuristic use of perceptual evidence leads to dissociation between performance and metacognitive sensitivity. Attention, Perception \& Psychophysics, 78, 923-937. https://doi.org/10.3758/s13414-016-1059-х

Marcel, A. J. (1986). Consciousness and processing: Choosing and testing a null hypothesis. Behavioral and Brain Sciences, 9(1), 40-41. https://doi.org/10.1017/S0140525X0002143

Marshall, J. C., \& Halligan, P. W. (1988). Blindsight and insight in visuospatial neglect. Nature, 336, 766-67. https://doi.org/10.1038/336766a0

Masatoshi, Y., \& Isa, T. (2015). Signal detection analysis of blindsight in monkeys. Scientific Reports, 5, 10755. https://doi.org/10.1038/srep10755

Mazzi, C., Bagattini, C., \& Savazzi, S. (2016). Blind-sight vs. degraded-sight: different measures tell a different story. Frontiers in Psychology, 7(901), 1-11. https://dx.doi.org/10.3389/fpsyg.2016.00901

Mazzi, C., Savazzi, S., \& Silvanto, J. (2019). On the "blindness" of blindsight: What is the evidence for phenomenal awareness in the absence of primary visual cortex (V1)? Neuropsychologia, 128, 103-108. https://doi.org/10.1016/j.neuropsychologia.2017.10.029 
Merikle, P. M., Smilek, D., \& Eastwood, J. D. (2001). Perception without awareness:

perspectives from cognitive psychology. Cognition, 79(1-2), 115-134.

https://doi.org/10.1016/s0010-0277(00)00126-8

Milner, D. (1998). Insights into blindsight. Trends in Cognitive Sciences, 2(7), 237-8.

https://doi.org/10.1016/S1364-6613(98)01185-1

Milner, D., \& Goodale, M. A. (2006 [1st edition 1995]) The Visual Brain in Action. Oxford:

Oxford University Press.

Milner, A. D., \& Goodale, M. A. (2008). Two visual systems re-viewed. Neuropsychologia, 46(3), 774-785. https://doi.org/10.1016/j.neuropsychologia.2007.10.005

Miyoshi, K., \& Lau, H. (2020). A decision-congruent heuristic gives superior metacognitive sensitivity under realistic variance assumptions. Psychological Review. Advance online publication. https://doi.org/10.1037/rev0000184

Morgan, M., Dillenburger, B., Raphael, S., \& Solomon, J. A. (2012). Observers can voluntarily shift their psychometric functions without losing sensitivity. Attention, Perception, \& Psychophysics, 74(1), 185-193. https://doi.org/10.3758/s13414-011-0222-7

Morland, A. B., Jones, S. R., Finlay, A. L., Deyzac, E., Lê, S., \& Kemp, S. (1999). Visual perception of motion, luminance and colour in a human hemianope. Brain, 122(6), 11831198. https://doi.org/10.1093/brain/122.6.1183

Morland, A. B., Lê, S., Carroll, E., Hoffmann, M. B., \& Pambakian, A. (2004). The role of spared calcarine cortex and lateral occipital cortex in the responses of human hemianopes to 
visual motion. Journal of Cognitive Neuroscience, 16(2), 204-218.

https://doi.org/10.1162/089892904322984517

Morland, A. B., Ogilvie, J. A., Ruddock, K. H, \& Wright, J. R. (1996). Orientation

discrimination is impaired in the absence of the striate cortical contribution to human vision.

Proceedings of the Royal Society of London. Series B, Biological Sciences, 263(1370), 633-640.

https://doi.org/10.1098/rspb.1996.0095

Morris, J. S., de Gelder, B., Weiskrantz, L., \& Dolan, R. J. (2001). Differential

extrageniculostriate and amygdala responses to presentation of emotional faces in a cortically

blind field. Brain, 124(6), 1241-52. https://doi.org/10.1093/brain/124.6.1241

Morsella, E. (2005). The function of phenomenal states: supramodular interaction theory. Psychological Review, 112(4), 1000-1021. https://doi.org/10.1037/0033-295X.112.4.1000

Nachmias, J. (1981). On the psychometric function for contrast detection. Vision Research, 21(2), 215-223. https://doi.org/10.1016/0042-6989(81)90115-2

Neuringer, A. (1986). Can people behave "randomly?": The role of feedback. Journal of Experimental Psychology: General, 115(1), 62-75. https://doi.org/10.1037/0096-3445.115.1.62

Newell, B. R., \& Shanks, D. R. (2014). Unconscious influences on decision making: A critical review. Behavioral and Brain Sciences, 37(1), 1-19.

https://doi.org/10.1017/S0140525X12003214

O’Brien, G., \& Opie, J. (1999). A connectionist theory of phenomenal experience. Behavioral and Brain Sciences, 22(1), 127-196. https://doi.org/10.1017/S0140525X9900179X 
Overgaard, M., Fehl, K., Mouridsen, K., Bergholt, B., \& Cleeremans, A. (2008). Seeing without seeing? Degraded conscious vision in a blindsight patient. PLOS ONE, 3(8), e3028. https://dx.doi.org/10.1371/journal.pone.0003028

Overgaard, M. (2011). Visual experience and blindsight: A methodological review. Experimental Brain Research, 209(4), 473-79. https://doi.org/10.1007/s00221-011-2578-2

Overgaard, M. (2012). Blindsight: recent and historical controversies on the blindness of blindsight. WIREs Cognitive Science, 3, 607-614. https://doi.org/10.1002/wcs.1194

Pascual-Leone, A., \& Walsh, V. (2001). Fast back-projections from the motion to the primary visual area necessary for visual awareness. Science, 292(5516), 510 -512.

https://doi.org/10.1126/science.1057099

Persaud, N., \& Cowey, A. (2008). Blindsight is unlike normal conscious vision: evidence from an exclusion task. Consciousness \& Cognition, 17(3), 1050-1055.

https://doi.org/10.1016/j.concog.2007.10.002

Persaud, N., \& Lau, H. C. (2008). Direct assessment of qualia in a blindsight participant. Consciousness \& Cognition, 17(3), 1046-9. https://doi.org/10.1016/j.concog.2007.10.001

Persaud, N., \& McLeod, P. (2008). Wagering demonstrates subconscious processing in a binary exclusion task. Consciousness \& Cognition, 17(3), 565-575.

https://doi.org/10.1016/j.concog.2007.05.003

Persaud, N., \& McLeod, P. (2014). Demonstrations of subconscious processing with the binary exclusion task. Behavioural and Brain Sciences, 37(1), 37.

https://doi.org/10.1017/S0140525X13000812 
Persaud, N., Davidson, M., Maniscalco, B., Mobbs, D., Passingham, R. E., Cowey, A., \&, Lau, H. (2011). Awareness-related activity in prefrontal and parietal cortices in blindsight reflects more than superior visual performance. NeuroImage, 58(2), 605-611. https://doi.org/10.1016/j.neuroimage.2011.06.081

Persaud, N., McLeod, P., \& Cowey, A. (2007). Post-decision wagering objectively measures awareness. Nature Neuroscience, 10(2), 257-261. https://doi.org/10.1038/nn1840

Peters, M. A. K., Ro, T., \& Lau, H. C. (2016). Who's afraid of response bias? Neuroscience of Consciousness, 1, 1-8. https://doi.org/10.1093/nc/niw001

Phillips, I. (2016). Consciousness and criterion: On Block’s case for unconscious seeing. Philosophy \& Phenomenological Research, 93(2), 419-451. https://doi.org/10.1111/phpr.12224

Phillips, I. (2018). The methodological puzzle of phenomenal consciousness. Philosophical Transactions of the Royal Society B, 373(1755): 20170347, 1-9.

http://doi.org/10.1098/rstb.2017.0347

Phillips, I. (2020). Making sense of blindsense: a commentary on Garric et al. 2019. Cortex, 127, 388-392. https://doi.org/10.1016/j.cortex.2019.11.016

Phillips, I. Forthcoming. Scepticism about unconscious perception is the default hypothesis. Journal of Consciousness Studies.

Pisella, L., Gréa, H., Tilikete, C., Vighetto, A., Desmurget, M., Rode, G., Boisson, D., \& Rossetti, Y. (2000). An 'automatic pilot' for the hand in human posterior parietal cortex: toward reinterpreting optic ataxia. Nature Neuroscience, 3(7), 729-736. https://doi.org/10.1038/76694 
Pöppel, E., Held, R., \& Frost, D. (1973). Residual visual function after brain wounds involving the central visual pathways in man. Nature, 243(5405), 295-296.

https://doi.org/10.1038/243295a0

Price, M. C. (1991). Processing and awareness of masked stimuli. Unpublished Ph.D. Thesis, University of Cambridge.

Price, M. C. (2001). Now you see it, now you don't: Preventing consciousness with visual masking. In: Finding Consciousness in the Brain: A Neurocognitive Approach. P. G.

Grossenbacher (ed.). John Benjamins Publishing Company, pp. 25-60.

Ptito, A., \& Leh, S. E. (2007). Neural substrates of blindsight after hemispherectomy. The Neuroscientist, 13(5), 506-518. https://doi.org/10.1177/1073858407300598

Railo, H., Piccin, R., \& Lukasik, K. M. (2020). Subliminal perception can be predicted from prestimulus activity. bioRxiv preprint https://doi.org/10.1101/2020.01.06.896803

Ramsøy, T. Z., \& Overgaard, M. (2004). Introspection and subliminal perception.

Phenomenology and the Cognitive Sciences, 3, 1-23.

https://doi.org/10.1023/B:PHEN.0000041900.30172.e8

Rosenthal, D. (2019). Consciousness and confidence. Neuropsychologia, 128, 255-265. https://doi.org/10.1016/j.neuropsychologia.2018.01.018

Sahraie, A., Weiskrantz, L., Barbur, J. L., Simmons, A., Williams, S. C. R., \& Brammer, M. J. (1997). Pattern of neuronal activity with conscious and unconscious processing of signals. Proceedings of the National Academy of Sciences USA, 94(17), 9406-11. https://doi.org/10.1073/pnas.94.17.9406 
Sahraie, A., Weiskrantz, L., Trevethan, C. T., Cruce, R., \& Murray, A. D. (2002).

Psychophysical and pupillometric study of spatial channels of visual processing on blindsight. Experimental Brain Research, 143(2), 249-256. https://doi.org/10.1007/s00221-001-0989-1

Samaha, J., Barrett, J. J., Sheldon, A. D., LaRocque, J. J., \& Postle, B. R. (2016). Dissociating perceptual confidence from discrimination accuracy reveals no influence of metacognitive awareness on working memory. Frontiers in Psychology, 7(851), 1-8.

https://dx.doi.org/10.3389/fpsyg.2016.00851

Sand, A. (2016). Subliminal or not? Unpublished Ph.D. Thesis, Stockholm University.

Schacter, D., McAndrews, M. P., \& Moscovitch, M. (1988). Access to consciousness:

Dissociations between implicit and explicit knowledge in neuropsychological syndromes. In L. Weiskrantz (ed.). A Fyssen Foundation Symposium. Thought Without Language. Oxford: Oxford University Press, pp. 242-278.

Schenk, T. (2012). No dissociation between perception and action in patient DF when haptic feedback is withdrawn. Journal of Neuroscience, 32(6), 2013-7. https://doi.org/10.1523/JNEUROSCI.3413-11.2012

Schenk, T., \& McIntosh, R. D. (2010). Do we have independent visual streams for perception and action? Cognitive Neuroscience, 1(1), 52-62. https://doi.org/10.1080/17588920903388950

Schulman, A. I., \& Mitchell, R. R. (1966). Operating characteristics from yes-no and forcedchoice procedures. The Journal of the Acoustical Society of America, 40(2), 473-477. https://doi.org/10.1121/1.1910098 
Schurger, A., \& Sher, S. (2008). Awareness, loss aversion, and post-decision wagering. Trends in Cognitive Sciences, 12(6), 209-210. https://doi.org/10.1016/j.tics.2008.02.012

Seth, A. K. (2008). Post-decision wagering measures metacognitive content, not sensory consciousness. Consciousness \& Cognition, 17(3), 981-983.

\section{https://doi.org/10.1016/j.concog.2007.05.008}

Seth, A. K., Dienes, Z., Cleeremans, A., Overgaard, M., \& Pessoa, L. (2008). Measuring consciousness: relating behavioural and neurophysiological approaches. Trends in Cognitive Sciences, 12(8), 314-321. https://doi-org.proxy1.library.jhu.edu/10.1016/j.tics.2008.04.008

Shekhar, M., \& Rahnev, D. (2020). The nature of metacognitive inefficiency in perceptual decision making. https://doi.org/10.31234/osf.io/g9qzh

Sidis, B. (1898). The Psychology of Suggestion. New York: Appleton.

Silvanto, J. (2008). A re-evaluation of blindsight and the role of striate cortex (V1) in visual awareness. Neuropsychologia, 46(12), 2869-71.

https://doi.org/10.1016/j.neuropsychologia.2008.04.014

Silvanto, J. (2015). Why is "blindsight" blind? A new perspective on primary visual cortex, recurrent activity and visual awareness. Consciousness \& Cognition, 32, 15-32. https://doi.org/10.1016/j.concog.2014.08.001

Silvanto, J., Cowey, A., Lavie, N., \& Walsh, V. (2005). Striate cortex (V1) activity gates awareness of motion. Nature Neuroscience, 8(2), 143-144. https://doi.org/10.1038/nn1379

Smithies, D. (2016). Perception and the external world. Philosophical Studies, 173(4), 11191145. 
Smits, A. R., Seijdel, N., Scholte, H. S., Heywood, C. A., Kentridge, R. W., \& de Haan, E. H. F. (2019). Action blindsight and antipointing in a hemianopic patient. Neuropsychologia, 128, 270275. https://doi.org/10.1016/j.neuropsychologia.2018.03.029

Snodgrass, M. (2002). Disambiguating conscious and unconscious influences: Do exclusion paradigms demonstrate unconscious perception? American Journal of Psychology, 115(4), 545579.

Snodgrass, M., \& Shevrin, H. (2006). Unconscious inhibition and facilitation at the objective detection threshold: Replicable and qualitatively different unconscious perceptual effects. Cognition, 101 (1), 43-79. https://doi.org/10.1016/j.cognition.2005.06.006

Snodgrass, M., Kalaida, N., \& Winer, E. S. (2009a). Access is mainly a second-order process: SDT models whether phenomenally (first-order) conscious states are accessed by reflectively (second-order) conscious processes. Consciousness \& Cognition,18(2), 561-564. https://doi.org/10.1016/j.concog.2009.01.003

Snodgrass, M., Winer, E. S., \& Kalaida, N. (2009b). Perception: Subliminal and Implicit. In: Encyclopedia of Consciousness Vol. 2, W. P. Banks (ed.). Academic Press, pp. 135-146.

Sperling, G. (1965). Temporal and spatial visual masking: I. Masking by impulse flashes. Journal of the Optical Society of America, 55(5), 541-549. https://doi.org/10.1364/JOSA.55.000541

Sperling, G., \& Lu, Z.-L. (1998). A systems analysis of visual motion perception. In: High-Level Motion Processing: Computational, Neurobiological, and Psychophysical Perspectives, T. Watanabe (ed.). Cambridge: MIT Press, pp. 154-183. 
Steinman, R. M., Pizlo, Z., \& Pizlo, F. J. (2000). Phi is not beta, and why Wertheimer's discovery launched the Gestalt revolution. Vision Research, 40(17), 2257-2264. https://doi.org/10.1016/s0042-6989(00)00086-9

Stoerig, P. (2006). Blindsight, conscious vision, and the role of primary visual cortex. Progress in Brain Research, 155, 217-34. https://doi.org/10.1016/S0079-6123(06)55012-5

Stoerig, P. (2010). Cueless blindsight. Frontiers in Human Neuroscience, 3(74), 1-8. https://doi.org/10.3389/neuro.09.074.2009

Stoerig, P., \& Barth, E. (2001). Low-level phenomenal vision despite unilateral destruction of primary visual cortex. Consciousness \& Cognition, 10(4), 574-587. https://doi.org/10.1006/ccog.2001.0526

Stoerig, P., \& Cowey, A. (1992). Wavelength discrimination in blindsight. Brain, 115(2), 425444. https://doi.org/10.1093/brain/115.2.425

Stoerig, P., Zontanou, A., \& Cowey, A. (2002). Aware or unaware: assessment of cortical blindness in four men and a monkey. Cerebral Cortex, 12(6), 565-574. https://doi.org/10.1093/cercor/12.6.565

Squire, L. R. (2009). Memory and brain systems: 1969-2009. Journal of Neuroscience, 29, 12711-12716. https://doi.org/10.1523/JNEUROSCI.3575-09.2009

Tamietto, M., Cauda, F., Corazzini, L. L., Savazzi, S., Marzi, C. A., Goebel, R., Weiskrantz, L., \& de Gelder, N. (2010). Collicular vision guides nonconscious behaviour. Journal of Cognitive Neuroscience, 22(5), 888-902. https://doi.org/10.1162/jocn.2009.21225 
Tapp, T. D. (1997). Blindsight in hindsight. Consciousness \& Cognition, 6(1), 67-74.

\section{https://doi.org/10.1006/ccog.1996.0267}

Tong, F. (2003). Primary visual cortex and visual awareness. Nature Reviews Neuroscience, 4(3), 219-229. https://doi.org/10.1038/nrn1055

Treisman, M., \& Faulkner, A. (1987). Generation of random sequences by human subjects: Cognitive operations or psychological process? Journal of Experimental Psychology: General, 116(4), 337-355. https://doi.org/10.1037/0096-3445.116.4.337

Treisman, M., \& Williams, T. C. (1984). A theory of criterion setting with an application to sequential dependencies. Psychological Review, 91(1), 68-111. https://doi.org/10.1037/0033$\underline{295 X .91 .1 .68}$

Treisman, M., \& Watts, T. R. (1966). Relation between signal detectability theory and the traditional procedures for measuring sensory thresholds: Estimating $d^{\prime}$ from results given by the method of constant stimuli. Psychological Bulletin, 66(6), 438-454. https://doi.org/10.1037/h0020413

Trevethan, C. T., Sahraie, A., \& Weiskrantz, L. (2007). Can blindsight be superior to 'sighted sight'? Cognition, 103(3), 491-501. https://doi.org/10.1016/j.cognition.2006.04.011

Tulving, E., \& Schacter, D. L. (1990). Priming and human memory systems. Science, 247(4940), 301-306. https://doi.org/10.1126/science.2296719

Veale, R., Hafed, Z. M., \& Yoshida, M. (2017). How is visual salience computed in the brain? Insights from behaviour, neurobiology and modelling. Philosophical Transactions of the Royal 
Society of London B: Biological Sciences, 372(1714), 20160113.

https://doi.org/10.1098/rstb.2016.0113

von Fieandt, K. (1966). The World of Perception. Homewood, IL: The Dorsey Press.

Weiskrantz, L. (1980). Varieties of residual experience. Quarterly Journal of Experimental

Psychology, 32(3), 365-386. http://dx.doi.org/10.1080/14640748008401832

Weiskrantz, L. (1987). Residual vision in a scotoma. A follow-up study of 'form' discrimination. Brain, 110(1), 77-92. https://doi.org/10.1093/brain/110.1.77

Weiskrantz, L. (1990). The Ferrier Lecture, 1989: Outlooks for blindsight: explicit methodologies for implicit processes. Proceedings of the Royal Society of London. Series B, Biological Sciences, 239(1296), 247-278. https://doi.org/10.1098/rspb.1990.0016

Weiskrantz, L. (1997). Consciousness lost and found. Oxford: Oxford University Press.

Weiskrantz, L. (1998a). Consciousness and commentaries. In: Toward a Science of Consciousness II. S. R. Hameroff, A. W. Kaszniak, \& A. C. Scott (eds). Cambridge, MA: MIT Press, pp. 371-77.

Weiskrantz, L. (1998b). Consciousness and commentaries. International Journal of Psychology, 33(3), 227-233. https://doi.org/10.1080/002075998400411

Weiskrantz, L. (2001). Blindsight. In: Handbook of Neuropsychology ( $2^{\text {nd }}$ Edition), Volume 4:

Disorders of Visual Behavior. M. Behrmann (ed.). Amsterdam: Elsevier, pp. 215-237.

Weiskrantz, L. (2009a). Blindsight: A Case Study Spanning 35 Years and New Developments. Oxford: Oxford University Press. (Original edition published 1986.) 
Weiskrantz, L. (2009b). Is blindsight just degraded normal vision? Experimental Brain

Research, 192(3), 413-6. https://doi.org/10.1007/s00221-008-1388-7

Weiskrantz, L. (2010). Blindsight in hindsight. The Psychologist, 23(4): 356-8.

Weiskrantz, L., Barbur, J. L., \& Sahraie, A. (1995). Parameters affecting conscious versus unconscious visual discrimination with damage to the visual cortex (V1). Proceedings of the National Academy of Sciences USA, 92(13), 6122-6126. https://doi.org/10.1073/pnas.92.13.6122

Weiskrantz, L., Cowey, A., \& LeMare, C. (1998). Learning from the pupil: a spatial visual channel in the absence of V1 in monkey and human. Brain, 121(6), 1065-1072.

https://doi.org/10.1093/brain/121.6.1065

Weiskrantz, L., Cowey, A., \& Barbur, J. L. (1999). Differential pupillary constriction and awareness in the absence of striate cortex. Brain, 122(8), 1533-1538.

https://doi.org/10.1093/brain/122.8.1533

Weiskrantz, L., Harlow, A., \& Barbur, J. L. (1991). Factors affecting visual sensitivity in a hemianopic subject. Brain, 114(5), 2269-82. https://doi.org/10.1093/brain/114.5.2269

Weiskrantz, L., Rao, A., Hodinott-Hill, I., Nobre, A. C., \& Cowey, A. (2003). Brain potentials associated with conscious aftereffects induced by unseen stimuli in a blindsight subject.

Proceedings of the National Academy of Sciences USA, 100(18), 10500-10505. https://doi.org/10.1073/pnas.1734039100

Weiskrantz, L., Warrington, E. K., Sanders, M. D., \& Marshall, J. (1974). Visual capacity in the hemianopic field following a restricted occipital ablation. Brain, 97(4), 709-728.

https://doi.org/10.1093/brain/97.1.709 
Wickelgren, W. A. (1968). Unidimensional strength theory and component analysis of noise in absolute and comparative judgments. Journal of Mathematical Psychology, 5(1), 102-

122. https://doi.org/10.1016/0022-2496(68)90059-X

Williams Jr., A. C. (1938). Perception of subliminal visual stimuli. Journal of Psychology, 6(1), 187-199. https://doi.org/10.1080/00223980.1938.9917596

Witt, J. K., Taylor, J. E. T., Sugovic, M., \& Wixted, J. T. (2015). Signal detection measures cannot distinguish perceptual biases from response biases. Perception, 44(3), 289-300. https://doi.org/10.1068/p7908

Wixted, J. T., Vul, E., Mickes, L., \& Wilson, B. M. (2018). Models of lineup memory. Cognitive Psychology, 105, 81-114. https://doi.org/10.1016/j.cogpsych.2018.06.001

Yeshurun, Y., Carrasco, M., \& Maloney, L. T. (2008). Bias and sensitivity in two-interval forced choice procedures: Tests of the difference model. Vision Research, 48(17), 1837-51. https://doi.org/10.1016/j.visres.2008.05.008

Zeki, S., \& ffytche, D. H. (1998). The Riddoch Syndrome: insights into the neurobiology of conscious vision. Brain, 121(1), 25-45. https://doi.org/10.1093/brain/121.1.25

Zylberberg, A., Barttfeld, P., \& Sigman, M. (2012). The construction of confidence in a perceptual decision. Frontiers in Integrative Neuroscience, 6(79), 1-10. https://doi.org/10.3389/fnint.2012.00079 


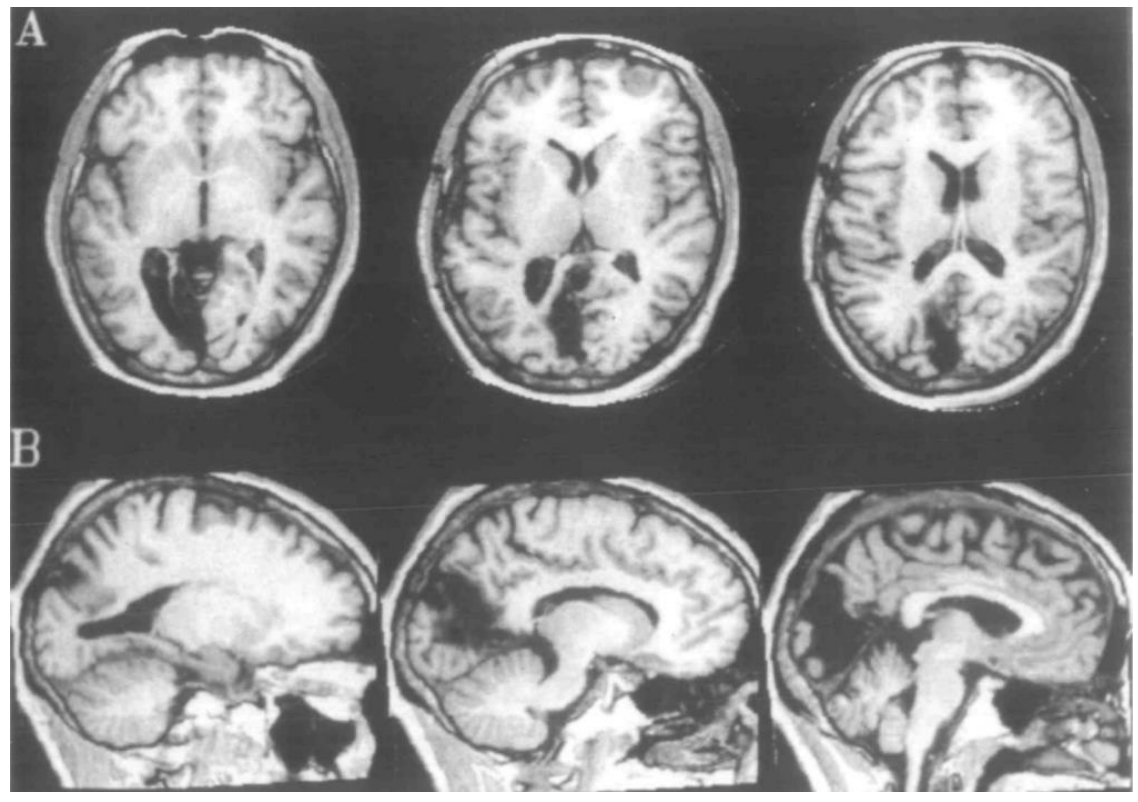

Figure 1. MRI of GY's brain showing transverse (A) and sagittal (B) sections. Note the nearly complete destruction of V1 in the left hemisphere. Reprinted from Barbur et al., 1993: 1295, Figure 1, Copyright () 1993, with permission from Oxford University Press. 


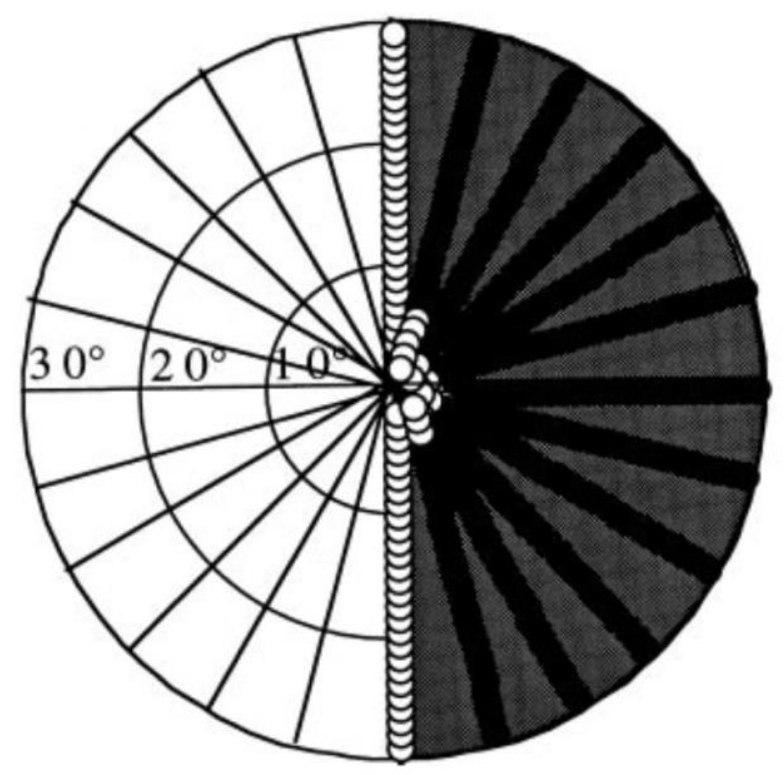

Figure 2. Static perimetry results for GY. White circles indicate positive responses. Black circles (which form radii extending along the tested meridians) indicate negative responses. Reprinted from Stoerig \& Barth, 2001: 575, Figure 1, Copyright (C) 2001, with permission from Elsevier. 


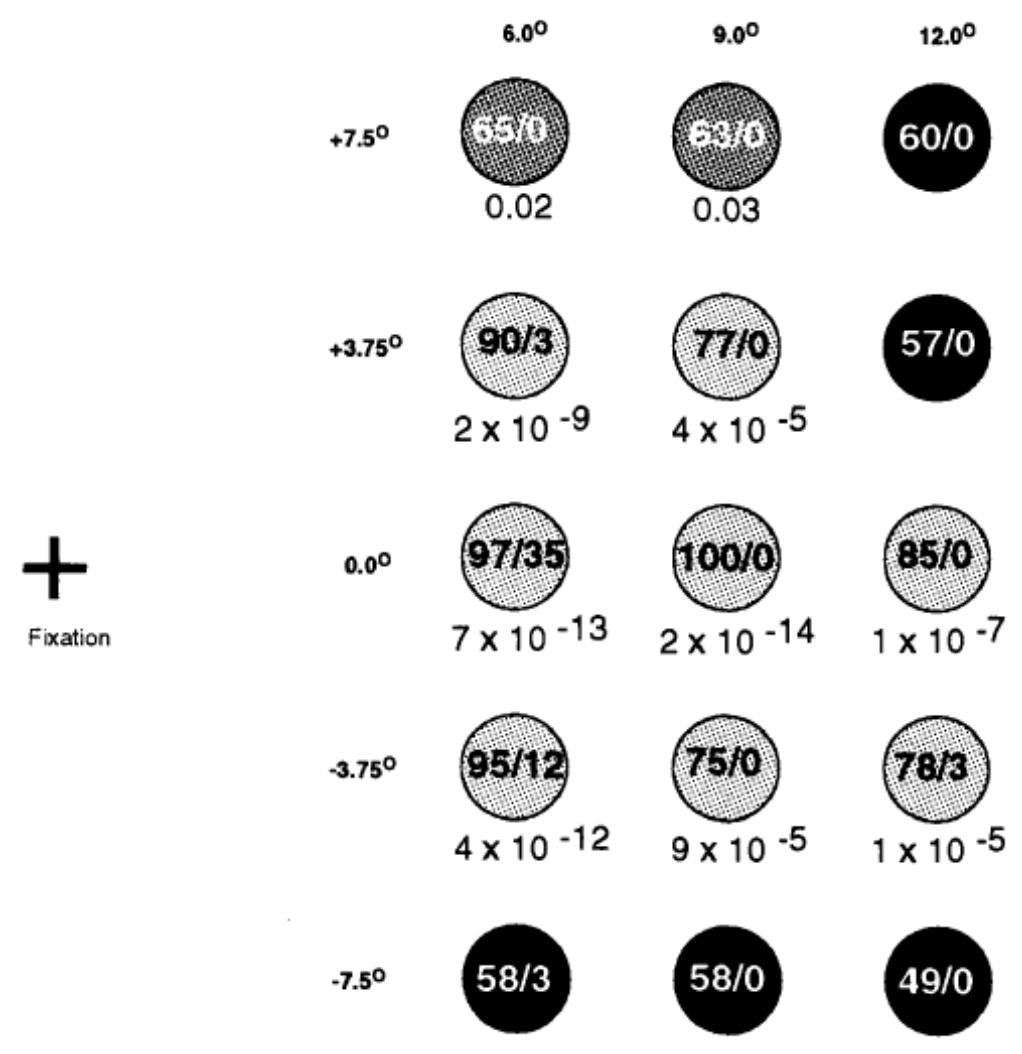

Figure 3. Data from a temporal 2ifc detection task with GY. A high contrast black $1^{\circ}$ diameter circle was flashed three times over in the first or second of two $600 \mathrm{msec}$ intervals. The first number in each circle indicates the number of correct responses out of a hundred. The second number in the circle indicates number of instances of reported awareness. The number below the circle indicates the odds of the performance resulting from pure guessing. From Kentridge et al., 1997: 193, Figure 2, Copyright (C) 1997, reprinted courtesy of The MIT Press. 


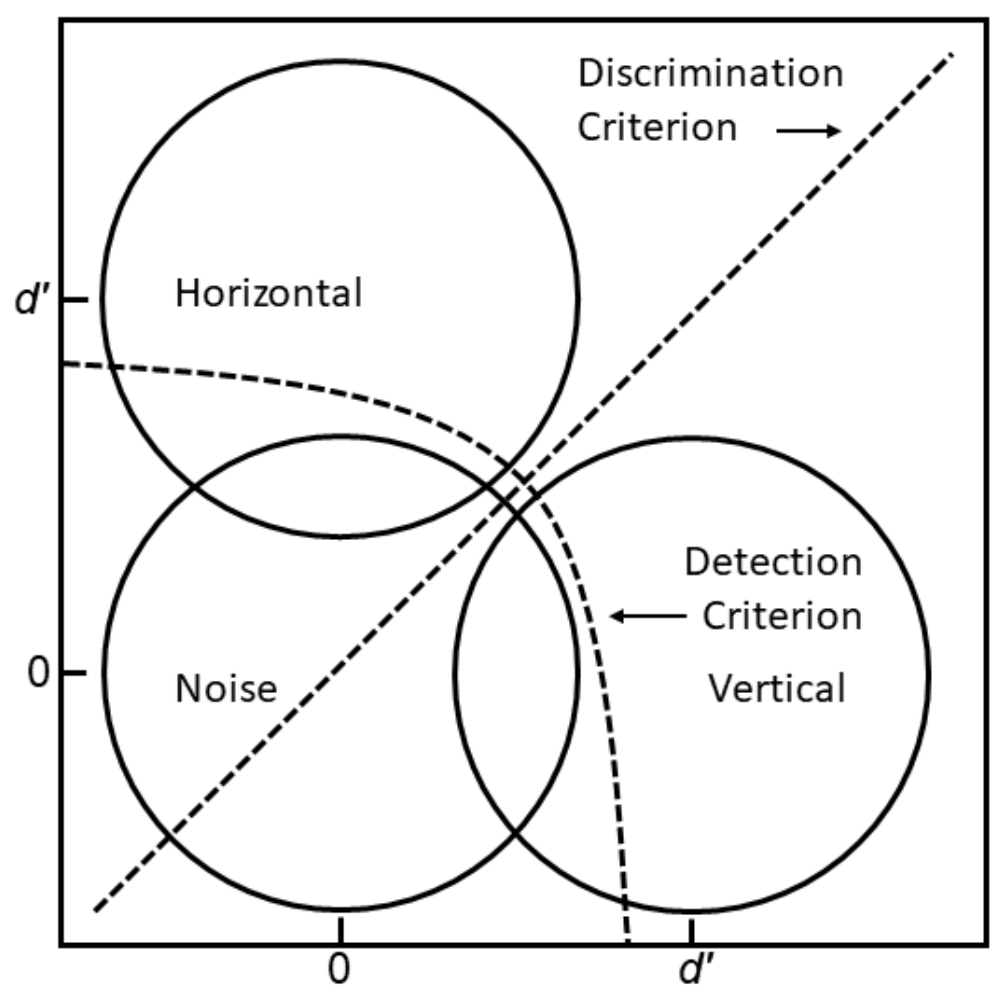

Figure 4. Theoretical decision space for horizontal/vertical task, based on Macmillan, 1986: 39, Figure 1. Given the depicted criteria, a substantial proportion of stimuli will elicit responses which will fall below the detection criterion (and so go undetected) but will nonetheless be discriminable as horizontal or vertical. 


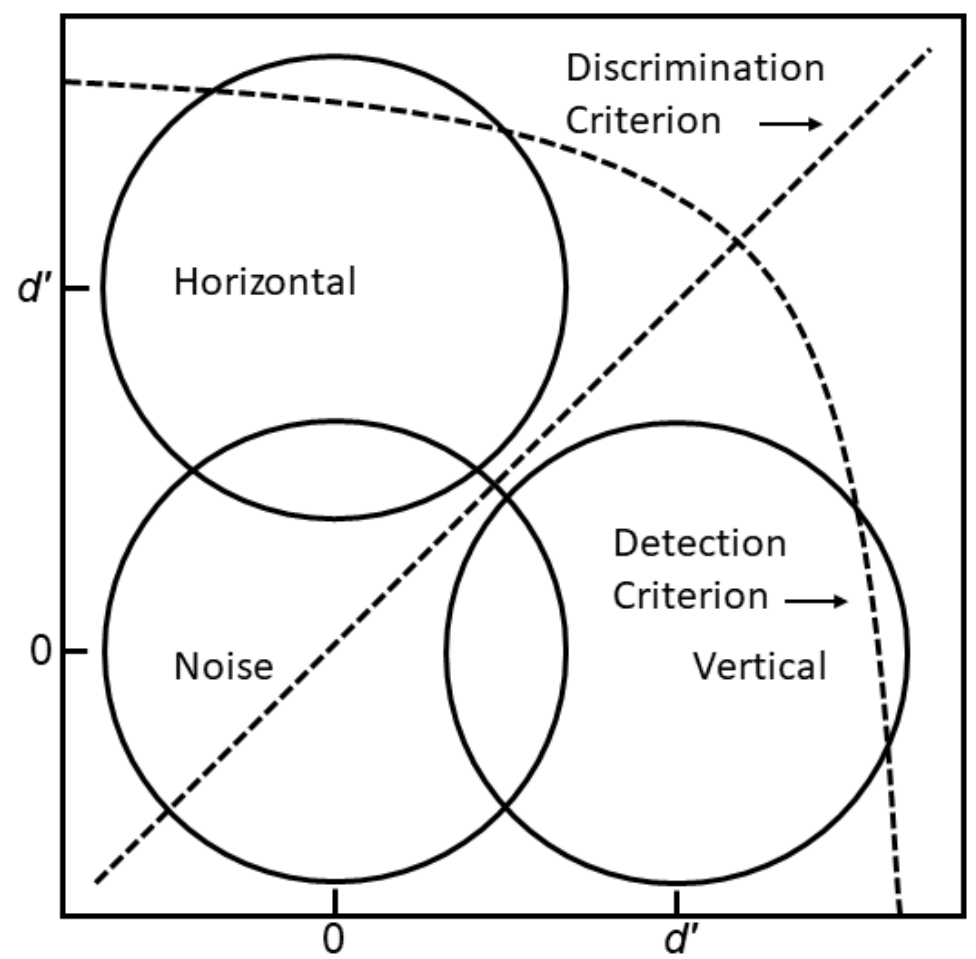

Figure 5. Theoretical decision space for horizontal/vertical discrimination in blindsight, accounting for significantly above-chance recognition despite an almost complete absence of acknowledged awareness. 


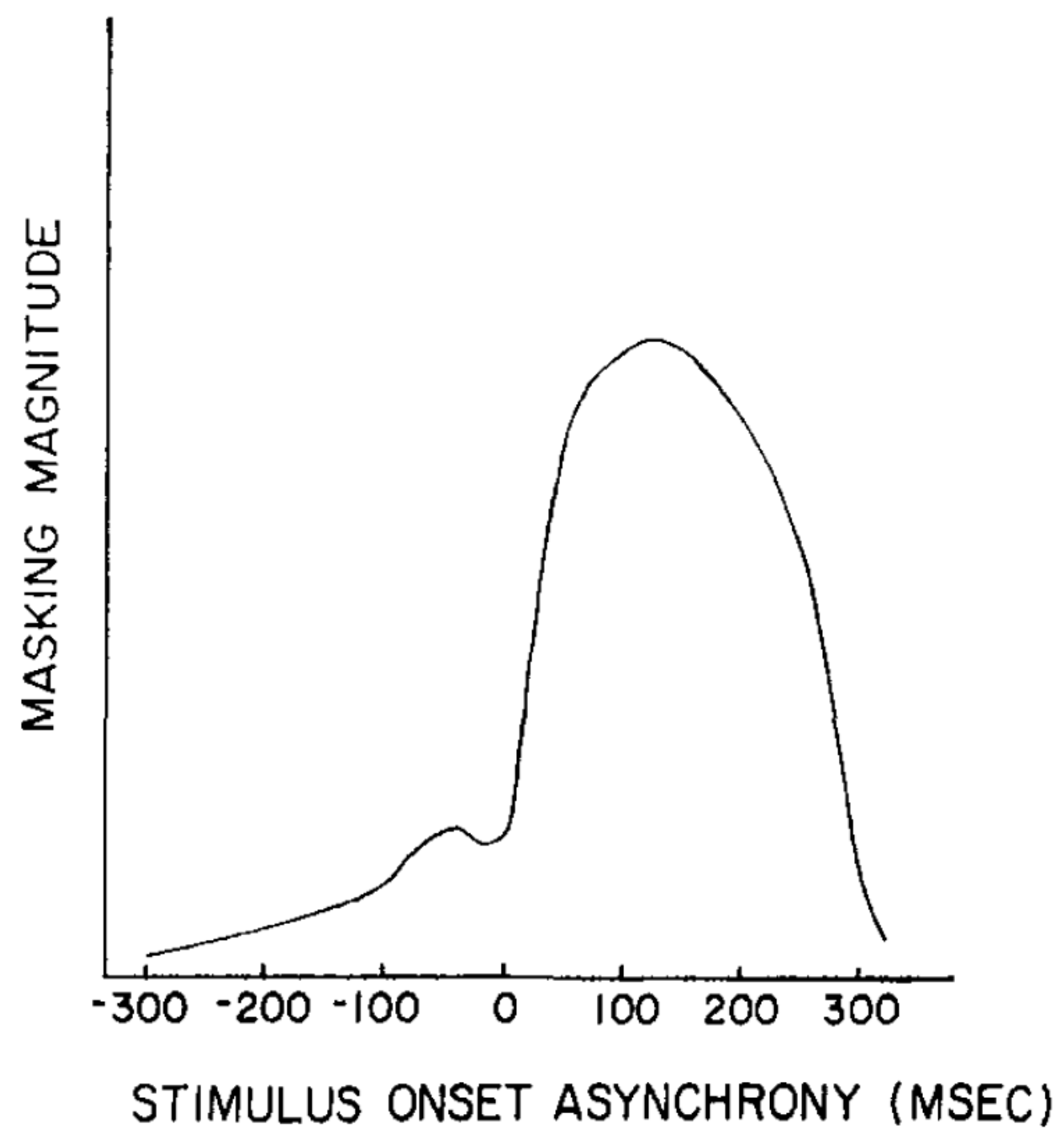

Figure 6. Characteristic non-monotonic metacontrast masking function. Adapted from Breitmeyer \& Ganz, 1976: 3, Figure 2 (B). (C 1976, American Psychological Association. 


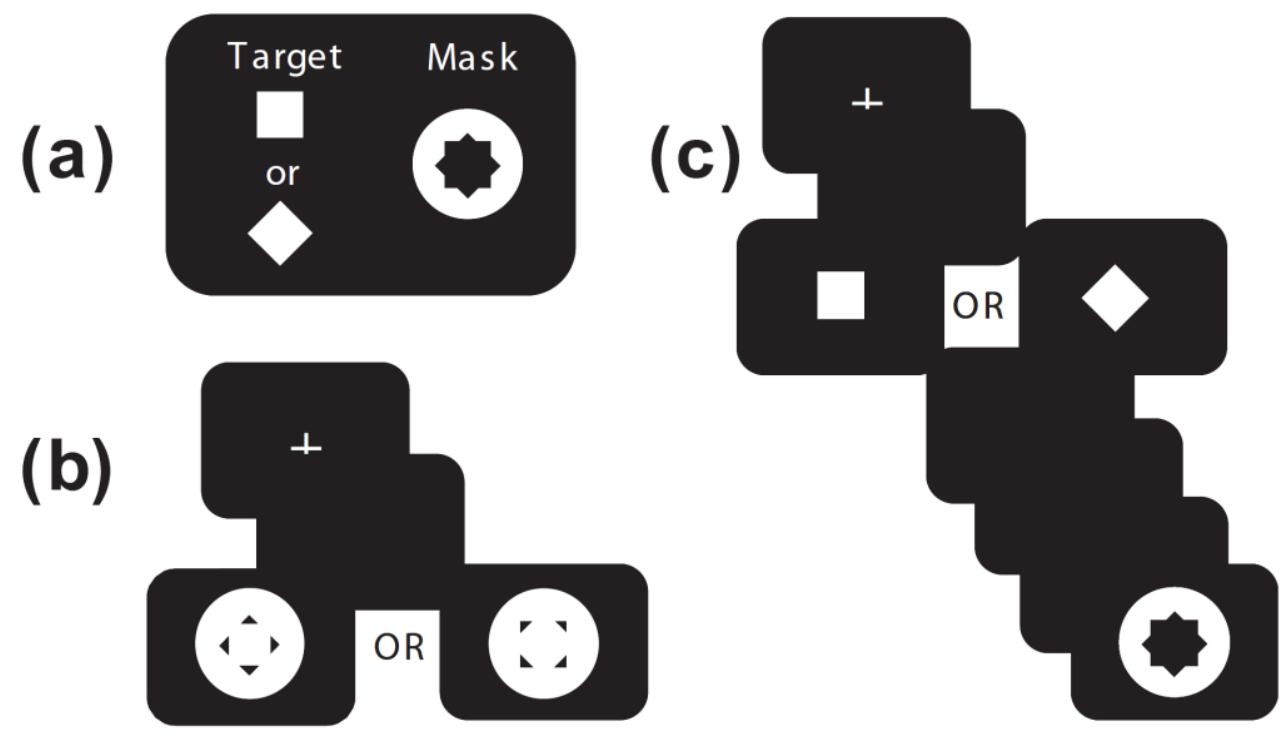

Figure 7. (a) Targets and metacontrast mask used in Lau \& Passingham, 2006: Exp. 1, (b) depiction of blended percept at 33ms SOA, (c) depiction of distinct object percepts at $104 \mathrm{~ms}$ SOA. Reprinted from Jannati \& Di Lollo, 2012: 308, Figure 1, Copyright @ 2012 , with permission from Elsevier. 

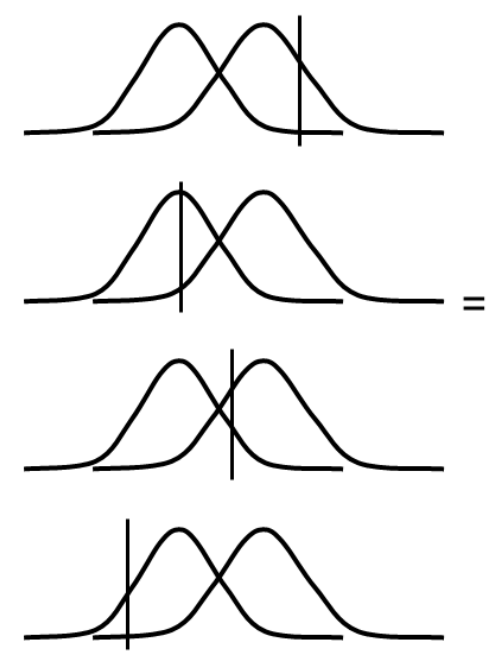

(a) 'Jittering' criterion
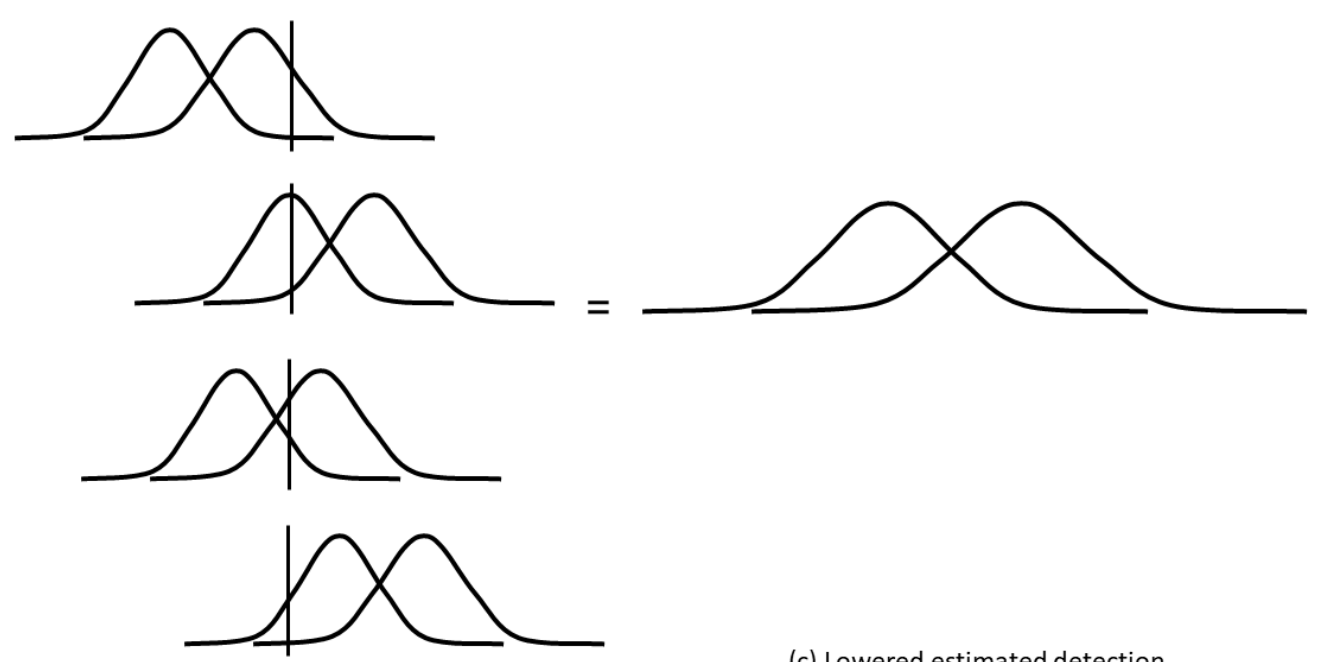

(b) 'Jittering' distributions (c) Lowered estimated detection sensitivity (higher apparent variance)

Figure 8. Graphical explanation of why criterion instability leads to lowered estimates of detection sensitivity in yn tasks. Jittering the criterion is formally equivalent to jittering signal and noise distributions which, averaged over trials, leads to an apparent increase in the variance of those distributions. This in turns leads to lower estimates of sensitivity as measured by the distance between the means of these distributions in units of their standard deviation (i.e. $d^{\prime}$ ). Redrawn from Ko \& Lau, 2012: Figure 3. 


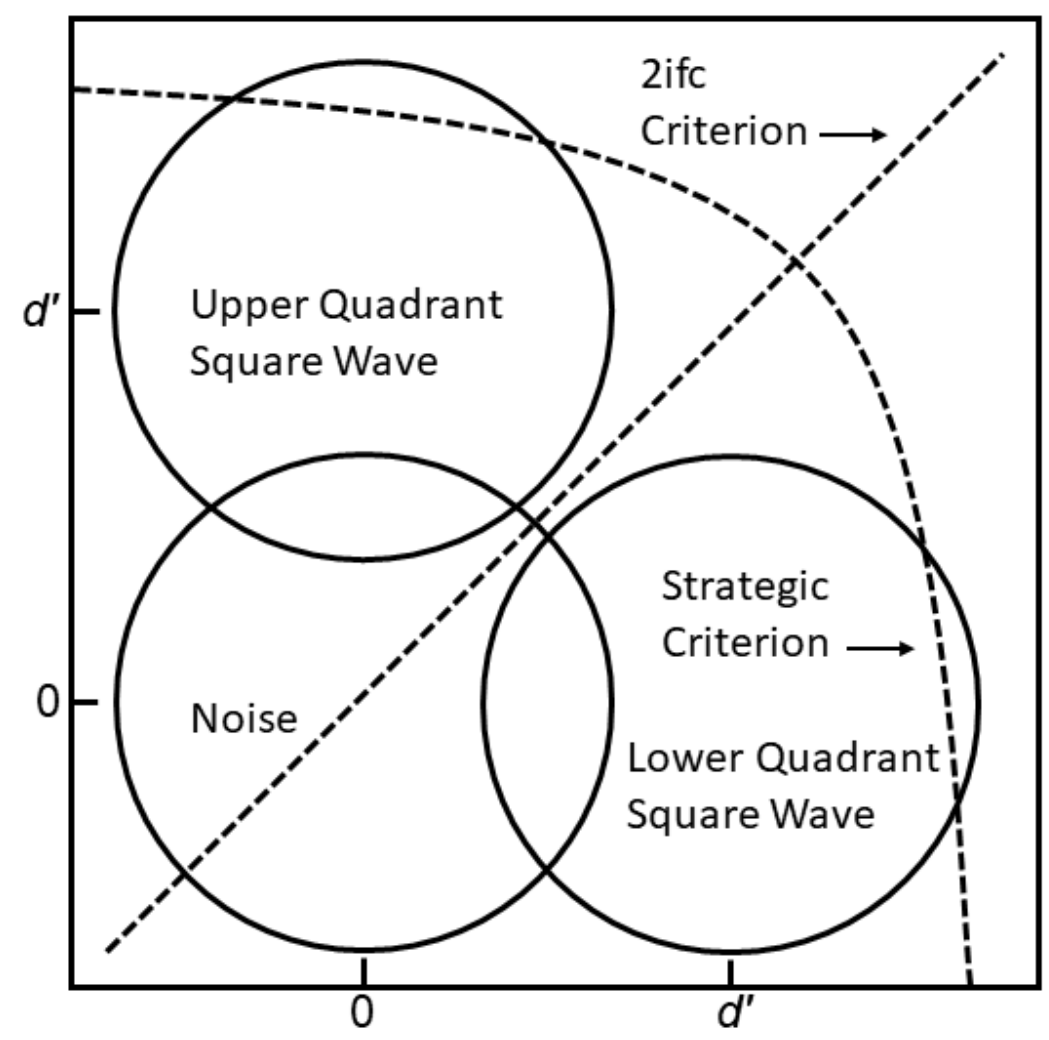

Figure 9. Theoretical decision space for spatial 2ifc task in Persaud \& Cowey, 2008. Under inclusion instructions, subjects adopt a symmetric 2ifc criterion choosing whichever quadrant is most likely to contain a signal. Under exclusion instructions, subjects continue to follow this strategy unless either signal exceeds a strategic criterion. If, as shown, this is highly conservative, subjects will continue to exhibit mainly inclusion behavior even under exclusion instructions. 

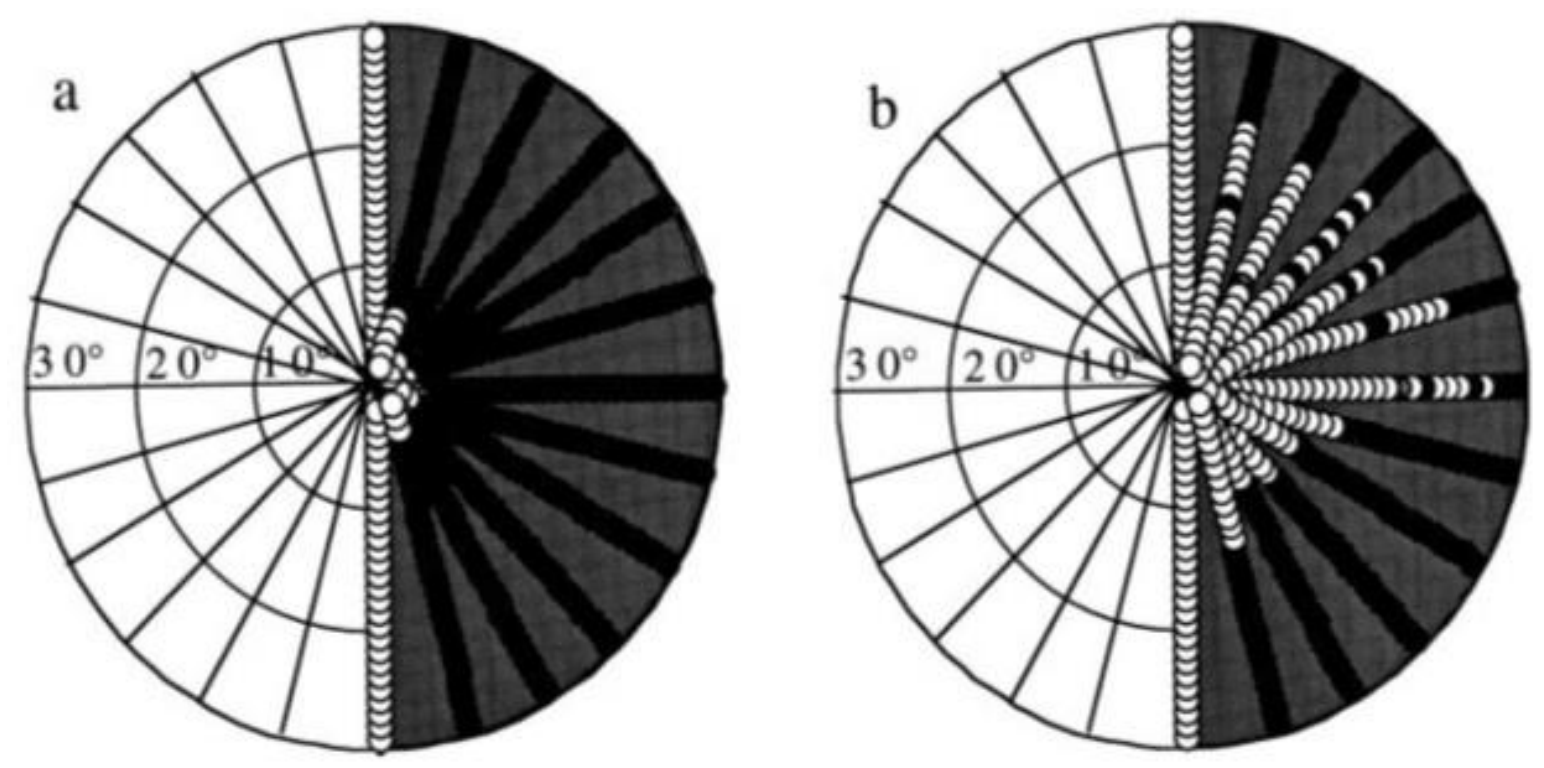

Figure 10. Static perimetry results for GY. White circles indicate positive responses, black circles (which form radii extending along the tested meridians) indicate negative responses. Instructions are (a) to 'press when you see something' and (b) to 'press when you are aware of something'. Reprinted from Stoerig \& Barth, 2001: 575, Figure 1, Copyright @ 2001 , with permission from Elsevier. 


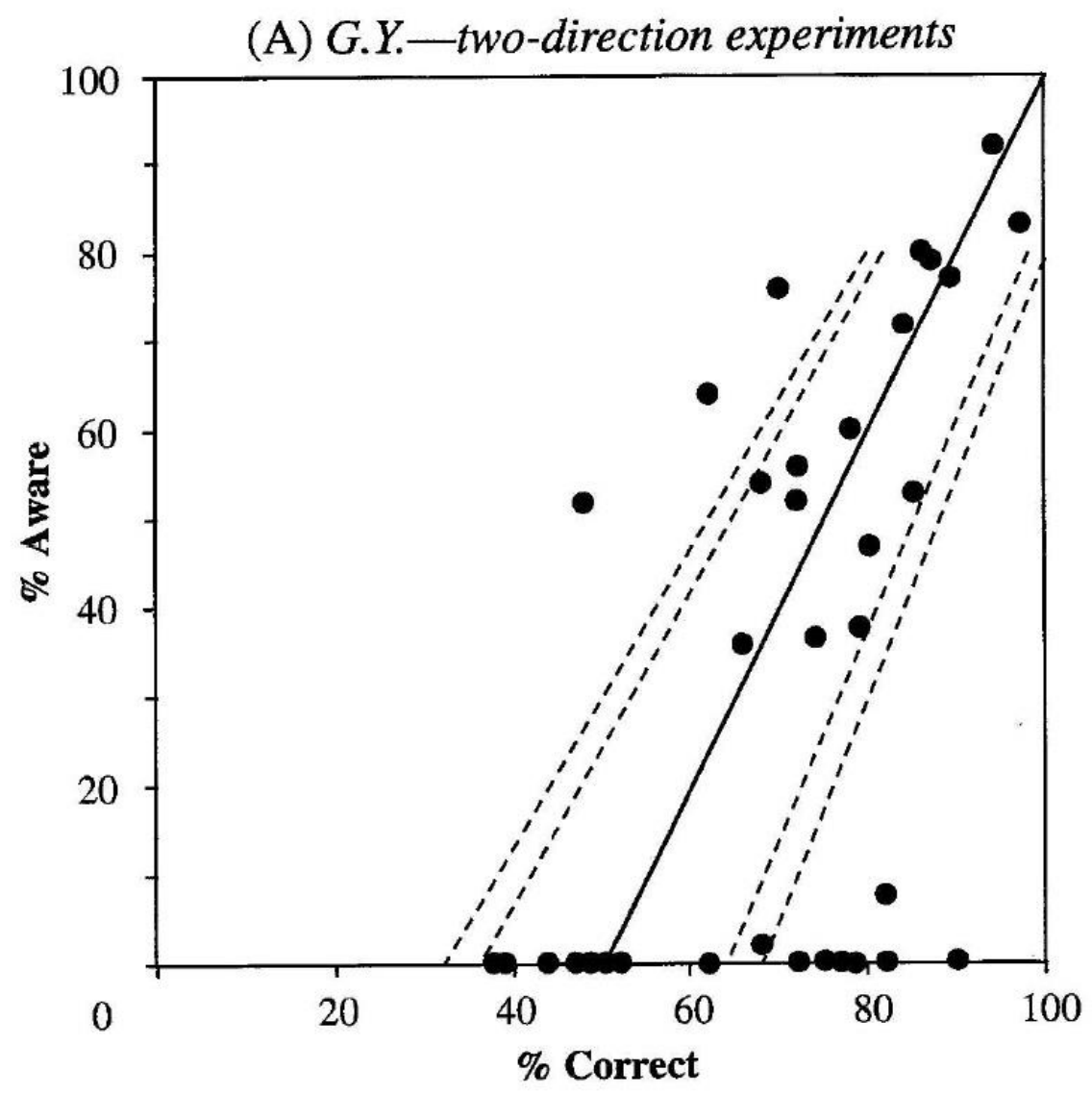

Figure 11. Data from two-direction experiments of Zeki \& ffytche, 1998. Each dot represents a block of 50 trials. The percentage of aware responses in each block is plotted against the percentage of correct motion discriminations. The thick line is the sum of (i) the number of aware trials in each block and (ii) the score expected by chance for the remaining unaware trials, the dotted lines represent the boundaries of the model under the binomial distribution at $P, 0.05$ and $P, 0.01$, respectively. I owe discussion of this example to Paul Azzopardi. Reprinted from Zeki \& ffytche, 1998: 32, Figure 2 (A), Copyright (C) 1998, with permission from Oxford University Press. 


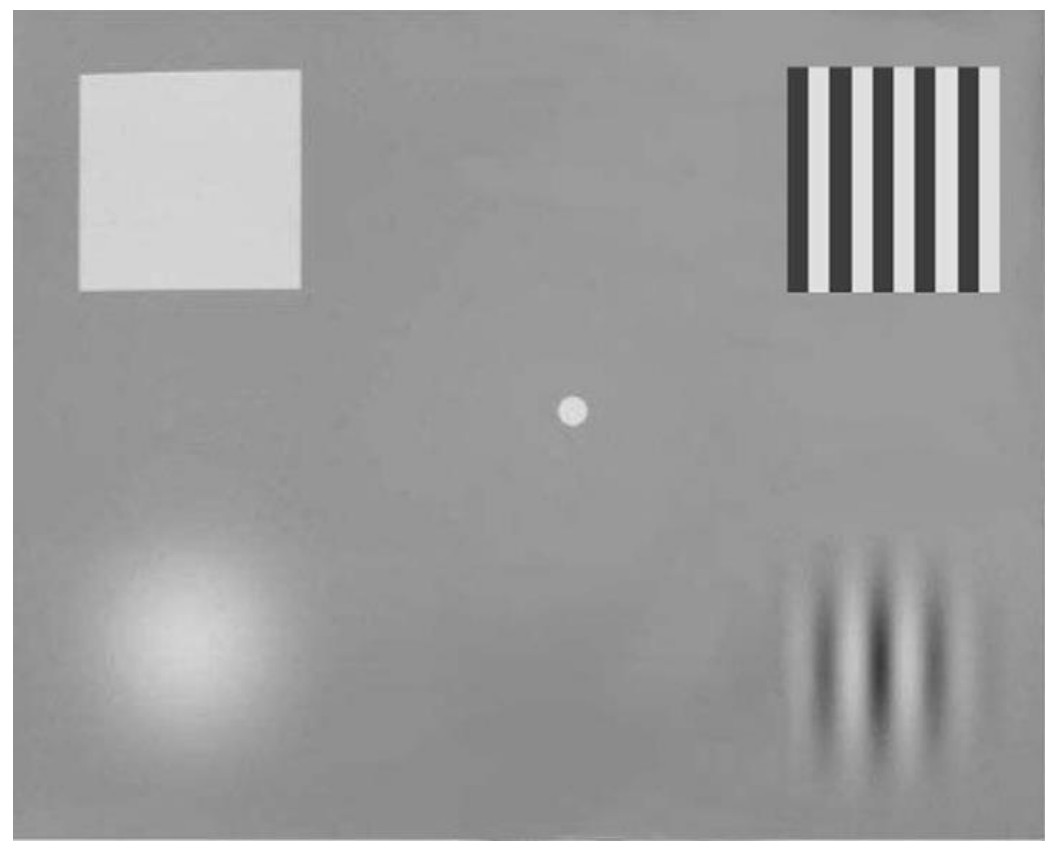

Figure 12. Stimuli from Alexander \& Cowey, 2010, Experiment 1. Clockwise from top left: square, square-wave, Gabor patch, and Gaussian. Only one stimulus was shown in one location per trial. Reprinted from Alexander \& Cowey, 2010: 522, Figure 1, Copyright (C) 2010, with permission from Elsevier. 


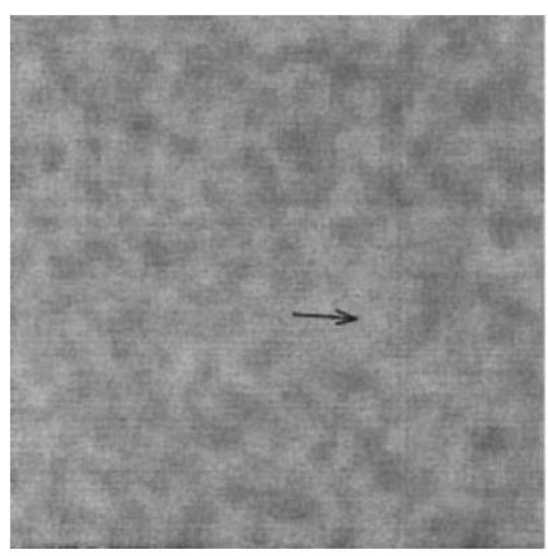

a

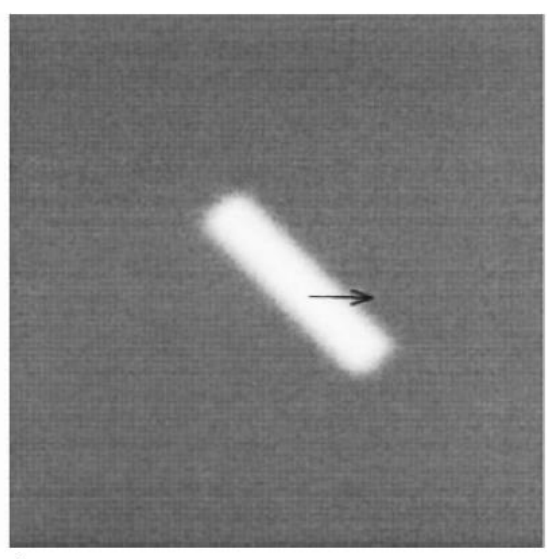

b

Figure 13. Frames from stimuli used to elicit phenomenal match across GY's sighted field (a) and blind field (b). Note that a texture defined moving bar is only seen in the dynamic stimulus depicted in (a). These dynamic stimuli can be viewed at: http://www.ebarth.de/demos/gy [last accessed 23 March 2020]. Reprinted from Stoerig \& Barth, 2001: 579, Figure 4, Copyright @ 2001, with permission from Elsevier. 


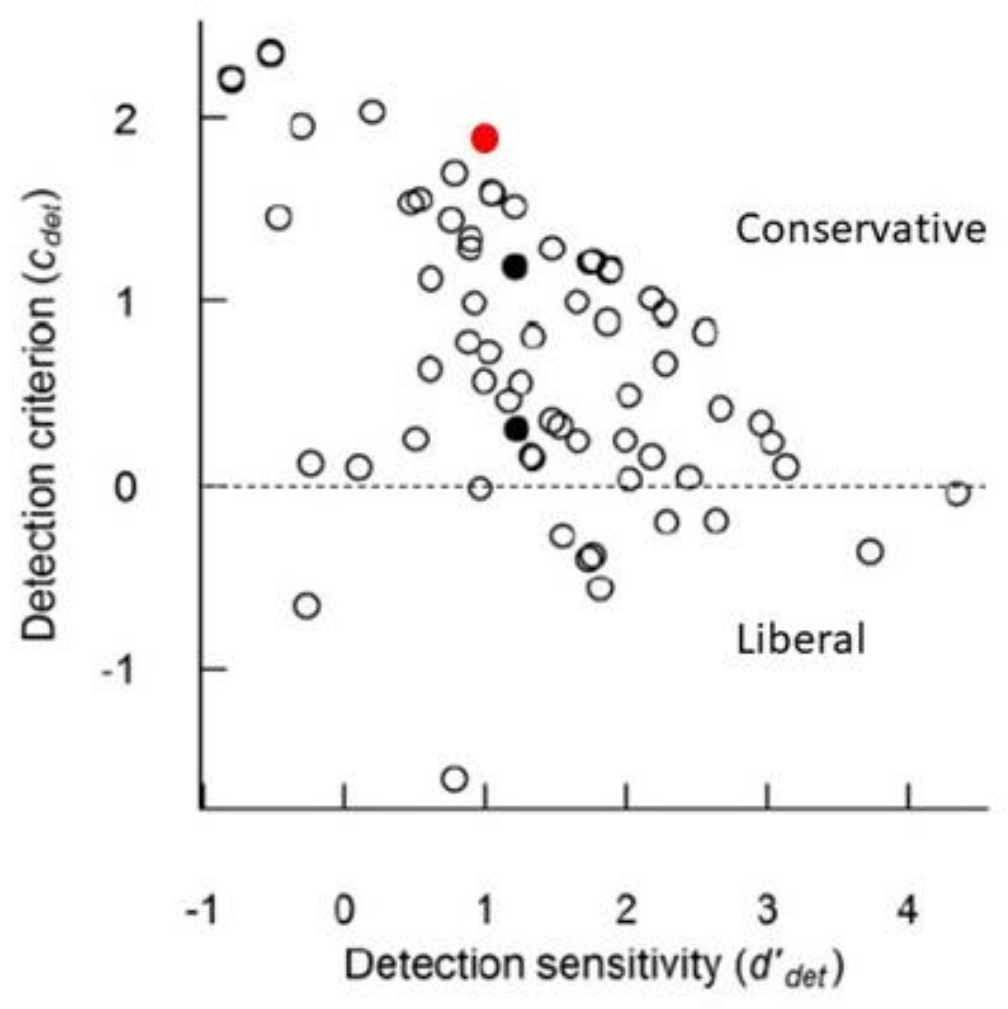

Figure 14. Relation between detection sensitivity and criterion in neurotypical subjects in Sand's (2016) metacontrast masking task (black and white circles), and in GY (red circle, based on Azzopardi \& Cowey, 1998). Adapted from Sand, 2016: 31, Figure 3, Copyright $(9) 2016$, with permission of Anders Sand. 